\title{
1 Microbiota-derived aspartate drives pathogenic Enterobacteriaceae expansion in the inflamed
}

2 gut

4 Woongjae Yoo ${ }^{1}$, Jacob K. Zieba ${ }^{1}$, Nicolas G. Shealy ${ }^{1}$, Teresa P. Torres ${ }^{1}$, Julia D. Thomas ${ }^{1}$, Catherine

$5 \quad$ D. Shelton ${ }^{1}$, Nora J. Foegeding ${ }^{1}$, Erin E. Olsan ${ }^{2}$ and Mariana X. Byndloss ${ }^{1,3,4,5^{*}}$

6

$7{ }^{1}$ Department of Pathology, Microbiology, and Immunology, Vanderbilt University Medical Center, 8 Nashville, TN 37232, USA.

9

${ }^{2}$ Department of Biological Sciences, California State University, Sacramento, CA 95819, USA.

${ }^{3}$ Vanderbilt Institute for Infection, Immunology, and Inflammation, Vanderbilt University Medical Center, Nashville, TN 37232, USA.

${ }^{4}$ Vanderbilt Digestive Disease Center, Vanderbilt University Medical Center, Nashville, TN 37232 , U.S.A.

${ }^{5}$ Vanderbilt Microbiome Innovation Center, Vanderbilt University, Nashville, TN 37235, U.S.A.

"Lead correspondence: mariana.x.byndloss@vumc.org 


\section{SUMMARY}

Inflammation boosts the availability of electron acceptors in the intestinal lumen creating a

39 favorable niche for pathogenic Enterobacteriaceae. However, the mechanisms linking intestinal 40 inflammation-mediated changes in luminal metabolites and pathogen expansion remain unclear. Here,

41 we show that mucosal inflammation induced by Salmonella enterica serovar Typhimurium (S. Tm)

42 infection and chemical colitis results in increased intestinal levels of the amino acid aspartate. The $S$.

$43 \mathrm{Tm}$ and E. coli genomes encode an aspartate ammonia-lyase (aspA) which converts aspartate into 44 fumarate, an alternative electron acceptor. S. Tm and pathogenic E. coli used aspA-dependent 45 fumarate respiration for growth in the murine gut only during inflammation. Such growth advantage was 46 abolished in the gut of germ-free mice. However, mono-association of gnotobiotic mice with members 47 of the classes Bacteroidia and Clostridia restored the benefit of aspartate utilization to the pathogens.

48 Our findings demonstrate the role of microbiota-derived amino acids in driving respiration-dependent

49 Enterobacteriaceae expansion during colitis.

51 Key words: Enterobacteriaceae, intestinal inflammation, microbial metabolism, amino acids, 52 microbiome, colonization resistance 


\section{INTRODUCTION}

The human gastrointestinal tract is colonized by a complex microbial community known as the gut microbiota. This community provides benefits to the host by contributing to nutrition and immune education (de Vos et al., 2022). In addition, the gut microbiota protects the host by limiting enteric pathogen expansion (colonization resistance) partially via nutrient sequestration (Caballero-Flores et al., 2020; Krautkramer et al., 2021; Oliphant and Allen-Vercoe, 2019). Enteric pathogens, such as Salmonella enterica serovar Typhimurium (S. Tm) and carcinogenic pks+ Escherichia coli (E. coli) have evolved to overcome colonization resistance by inducing and/or thriving during intestinal inflammation (colitis) (Arthur and Jobin, 2013; Arthur et al., 2014; Bronner et al., 2018; Faber et al., 2017; Shelton et al., 2022; Thiennimitr et al., 2011; Zhu et al., 2019). One of the critical mechanisms driving a luminal expansion of pathogenic Enterobacteriaceae during colitis is the generation of respiratory electron acceptors as a byproduct of the inflammatory host response. Electron acceptors enable $S$. Tm and pathogenic E. coli to use aerobic and anaerobic respiration to outcompete the resident microbiota and thus play a key role in altering intestinal microbiota composition during disease (Ali et al., 2014; Lopez et al., 2015, 2012; Rivera-Chavez et al., 2013; Thiennimitr et al., 2011; Winter et al., 2010). It is possible that not only the host, but also the gut microbiota may provide novel electron acceptors that support growth of enteric pathogens during gastroenteritis (Winter et al., 2010).

The crosstalk between the microbiota and enteric pathogens can be investigated by studying the flux of metabolites between microbes in the inflamed gut (Schrimpe-Rutledge et al., 2016; Tang et al., 2019; Zierer et al., 2018). Indeed, inflammation causes a significant change in the metabolic landscape of the gut, leading to the accumulation of a previously unknown set of nutrients that microorganisms inhabiting the intestinal lumen will need to compete for (Yoo et al., 2020). One metabolic interaction of interest is the microbiota's regulation of amino acids availability and utilization. Published studies demonstrate that commensal bacteria can reduce amino acid availability in the gut lumen, limiting early intestinal colonization by enteric pathogens (Caballero-Flores et al., 2020; Nguyen et al., 2020; Popp et al., 2015; Shealy et al., 2021). Amino acids are the building blocks of proteins and 
serve as intermediates in energy-producing cycles like the tricarboxylic acid cycle (TCA) and the urea

cycle (Akram, 2014; Morris, 2002; Salway, 2018). By sequestering amino acids, the microbiota limits

protein production and potential energy production by enteric pathogens. Thus, for a pathogen to

succeed in the gastrointestinal tract it must disrupt the microbiota restrictive processes such as amino

acid sequestration. The mechanisms used

by pathogenic Enterobacteriaceae to acquire and

metabolize amino acids to fuel expansion in the inflamed gut are largely unknown.

The S. Tm and E. coli genomes encode an aspartate-ammonia lyase (aspA) which enables the conversion of the amino acid aspartate into fumarate, an alternative electron acceptor (Falzone et al., 1988). S. Tm predominantly uses the fumarate reductase encoded by frd $A B C D$ genes under anaerobic or hypoxic conditions for expansion through fumarate respiration in the host gut during early infection (Arguello et al., 2010; Jones et al., 2007; Mercado-Lubo et al., 2008; Paiva et al., 2009). However, the major source of fumarate during later stages of $S$. Tm intestinal infection, and whether aspartatedependent fumarate respiration supports microbiota outgrowth by pathogenic Enterobacteriaceae in the inflamed gut remains unclear.

In this study, we show intestinal inflammation increases the abundance of the amino acid aspartate, which is dependent upon the presence of specific intestinal microbiota members. Previous studies suggest that dietary aspartate is the primary source of this amino acid in the intestinal lumen. Here, we use germ-free mouse models and dietary manipulations studies to demonstrate host and dietary aspartate do not contribute to elevated aspartate levels in the gut during inflammation. We show that $S$. Tm takes advantage of the increased aspartate pool in the intestinal lumen to outcompete the resident microbiota by converting aspartate into fumarate, an electron acceptor used for anaerobic respiration. Further, we demonstrate that increased microbiota-derived aspartate leads to carcinogenic pks+ E. coli expansion in the gut during colitis (DSS model of colitis). Lastly, our results using bacterial mutants that cannot induce intestinal inflammation suggest that aspartate-dependent fumarate respiration does not contribute to early (and inflammation-independent) intestinal colonization by pathogenic Enterobacteriaceae. 


\section{RESULTS}

\section{Pathogenic Enterobacteriaceae relies on aspartate for growth during colitis}

Previous studies have suggested that intestinal inflammation changes the availability of amino acids

in the intestinal lumen (Kitamoto et al., 2020). However, it is unclear whether infectious or noninfectious colitis may affect intestinal levels of amino acids (e.g., aspartate) used by pathogenic

Enterobacteriaceae. To test the hypothesis that intestinal inflammation increases the availability of

aspartate in the gut lumen, we measured aspartate levels in fecal contents of mouse models of infectious and noninfectious colitis. We used CBA/J mice infected with $S$. Tm as the model of infectious

colitis, as this mouse strain develops pathogen-induced gastroenteritis in the absence of streptomycin-

treatment (Faber et al., 2017; Plant and Glynn, 1976; Rivera-Chávez et al., 2016). To induce colitis

independently of a pathogen (noninfectious colitis), we treated C57BI/6J mice with $2.5 \%$ dextran

sodium sulfate (DSS) in the drinking water for seven days. Indeed, we observed increased aspartate

levels in fecal samples from S. Tm-infected mice (Fig. 1A) and DSS-treated mice (Fig. 1B), providing

the initial evidence that intestinal inflammation increases aspartate availability through unknown mechanisms.

To investigate whether aspartate utilization conferred a fitness advantage to pathogenic Enterobacteriaceae under conditions relevant to intestinal disease (anaerobic conditions), we first generated S. Tm and pks+ E. coli SP15 mutants unable to use aspartate by deleting aspA (encoding aspartate ammonia-lyase). We determined the anaerobic growth of $S$. Tm wild-type and $\triangle a s p A$ isogenic mutant as well as $E$. coli SP15 wild-type and $\triangle a s p A$ isogenic mutant in minimal medium supplemented or not with $40 \mathrm{mM}$ glycerol (carbon source), $30 \mathrm{mM}$ aspartate and/or $40 \mathrm{mM}$ nitrate (electron acceptor). Aspartate alone did not promote growth of S. Tm (Fig. 1C) or E. coli SP15 strains (Fig. 1D), nor did the addition of both nitrate and aspartate to the media (Fig. S1A and S1B). Interestingly, S. Tm and E. coli SP15 were able to grow in minimal media supplemented with glycerol and aspartate, and such 
phenotype was abolished in S. Tm and E. coli SP15 $\triangle a s p A$ isogenic mutants (Fig. 1C and 1D). S. Tm

and E. coli SP15 $\triangle a s p A$ mutants were able to grow to similar levels as wild-type strains when glucose

was given as a carbon source (Fig. S1C and S1D), suggesting that their inability to grow under glycerol

and aspartate conditions was not due to an overall growth-defect. Taken together, our results show

that pathogenic Enterobacteriaceae do not use aspartate as a carbon source for fermentation or anaerobic respiration. Instead, our results show that $S$. Tm and carcinogenic $p k s+E$. coli use aspartate via aspA to metabolize carbon sources (e.g., glycerol) via anaerobic respiration which supports the growth of pathogenic Enterobacteriaceae in vitro under anaerobic conditions.

The finding that the amino acid aspartate can support anaerobic-respiration dependent growth of S. Tm and E. coli SP15 in vitro prompted us to test if pathogenic Enterobacteriaceae can use aspA to take advantage of the increased levels of aspartate in the inflamed gut (Fig. 1A-B). First, we intragastrically infected CBA/J mice with a 1:1 ratio of wild-type $S$. Tm and an isogenic $\triangle a s p A$ mutant and determined the competitive index between strains at day one, three, seven and ten post-infection. The growth advantage of the wild-type $S$. Tm over the $\triangle a s p A$ mutant significantly increased as disease progressed, reaching higher levels at day ten post-infection (Fig. 1E) when intestinal inflammation was established (Fig. 1F). To confirm that intestinal inflammation supports aspA-dependent growth by pathogenic Enterobacteriaceae, we repeated the competition experiment in the noninfectious colitis model. We intragastrically infected C57BI6/J mice with a 1:1 ratio of wild-type $E$. coli SP15 and an isogenic $\triangle a s p A$ mutant one day after beginning DSS treatment. We determined the competitive index between E. coli SP15 strains in feces at day eight post-infection (Fig. 1G), when intestinal inflammation was established (Fig. 1H). Interestingly, the wild-type E. coli SP15 strain was able to significantly outcompete an isogenic $\triangle a s p A$ mutant in the feces of DSS-treated mice, but not in mock treated animals (Fig. 1G). Taken together, our results suggest that inflammation-mediated changes to the intestinal environment may be necessary for aspartate-dependent intestinal expansion of pathogenic Enterobacteriaceae. 
Intestinal inflammation is required for aspartate dependent pathogenic Enterobacteriaceae

expansion in the inflamed gut

The marked expansion of wild-type S. Tm and E. coli SP15 over their respective aspA mutants during late stages of infection (Fig. 1E and 1G) was surprising, as previous reports suggested that aspartate utilization is required for early intestinal colonization by Enterobacteriaceae, before the onset of inflammation (Nguyen et al., 2020; Schubert et al., 2021). Our noninfectious colitis model provided the initial evidence that pathogenic Enterobacteriaceae does not rely on aspA-dependent aspartate utilization for growth in the colonic lumen in the absence of inflammation (Fig. 1G-H). To further assess whether intestinal inflammation is indeed required to support aspartate-dependent expansion of pathogenic Enterobacteriaceae, we repeated our infectious colitis mouse model (CBA/J mice) using an inflammation-deficient $S$. Tm strain ( $(i n v A \Delta s p i B)$. S. Tm uses two type III secretion systems (T3SS) to invade the intestinal epithelium and perform intracellular replication (Galán and Curtiss, 1989). A mutant strain $(\Delta i n v A \Delta s p i B)$ of $S$. Tm is defective in both T3SS and does not cause inflammation in a mouse model (Coombes et al., 2005; Raffatellu et al., 2009). Thus, we constructed an $\Delta a s p A$ mutant in the $S$. Tm inflammation-deficient strain and then infected CBA/J mice with an equal mixture of $\triangle i n v A \Delta s p i B$ and $\Delta i n v A \Delta s p i B \Delta a s p A$. The competitive index was determined one, three, seven and ten days after infection. In contrast to the competitive advantage observed for wild-type $S$. Tm over $\Delta a s p A$, no competitive advantage was observed for $\Delta i n v A \Delta s p i B$ over $\Delta i n v A \Delta s p i B \Delta a s p A$, revealing that inflammation is required for aspartate to be advantageous to $S$. Tm in the intestinal lumen (Fig. 2A). Histopathology analysis confirmed that infection with S. Tm $\Delta i n v A \Delta s p i B$ did not induce intestinal inflammation (Fig. 2B). The concentration of aspartate was measured in the feces of mice infected with wild-type or $\Delta i n v A \Delta s p i B$ and a significant difference in fecal aspartate levels was observed (Figure 2C) indicating that the lack of an advantage of $\triangle i n v A \Delta s p i B$ over $\Delta i n v A \Delta s p i B \Delta a s p A$ could be due to decreased levels of aspartate in $\triangle i n v A \Delta s p i B$-infected mice. To address this concern, we repeated the 
04 infectious colitis experiment and increased intestinal concentrations of aspartate in $\Delta$ invA $\Delta s p i B-$

05 infected mice by providing aspartate $(0.4 \%)$ in the drinking water throughout the experiment (Fig. 2D-

06 F). The aspartate supplementation restored the ability of the inflammation-deficient S. Tm strain to 07 outcompete an isogenic $\triangle a s p A$ mutant at ten days post-infection (Fig. 2D), in the absence of intestinal 08 inflammation (Fig. 2E). Aspartate supplementation in the drinking water significantly increased aspartate levels in the intestinal lumen of $S$. Tm $\Delta$ invA $\Delta$ spiB-infected mice (Fig. 2F). Our results demonstrate that inflammation-mediated increase in aspartate levels drive expansion of pathogenic 11 Enterobacteriaceae in the gut lumen during colitis.

Chemotaxis towards and transport of exogenous aspartate is required for pathogenic

14 Enterobacteriaceae expansion in the inflamed gut

aspartate and uptake of this amino acid. Methyl-accepting chemotaxis protein II (encoded by tar)

18 facilitates bacterial movement towards aspartate (Slocum and Parkinson, 1985), while C4-

dicarboxylate transporter (encoded by $d c u A$ ) uptakes exogenous aspartate and other dicarboxylates

such as malate (Nguyen et al., 2020). Thus, we sought to investigate whether genes related to

aspartate chemotaxis, uptake and utilization would be affected in pathogenic Enterobacteriaceae grown

in the presence of aspartate under anaerobic conditions. We determined the expression of the genes

$\operatorname{tar}, \operatorname{aspA}$ and $d u c A$ of wild-type $S$. Tm grown in minimal medium supplemented or not with $40 \mathrm{mM}$ glycerol (carbon source), $30 \mathrm{mM}$ aspartate and/or $40 \mathrm{mM}$ nitrate (electron acceptor). Growth of $S$. Tm

on aspartate alone or in combination with glycerol resulted in increased expression of $\operatorname{tar}$, aspA and

$d c u A$ when compared to $S$. Tm grown on glycerol alone (Fig. 3A). Additionally, growth of $S$. Tm on aspartate in the presence of glycerol resulted in increased expression of $d c u A$ and aspA when 
compared to bacteria grown in aspartate alone (Fig. 3A), confirming that expression of aspartate uptake

and utilization genes is induced under aspartate-dependent anaerobic respiration conditions in vitro.

Next, we determined whether transport of exogenous aspartate or chemotaxis towards this amino acid conferred a fitness advantage to $S$. Tm in vitro under anaerobic conditions. We assessed the anaerobic growth of $S$. Tm wild-type and $\Delta d c u A$ and $\Delta t a r$ isogenic mutants in minimal medium supplemented or not with $40 \mathrm{mM}$ glycerol (carbon source) and $30 \mathrm{mM}$ aspartate. S. Tm was able to grow in minimal medium supplemented with glycerol and aspartate (Fig. 3B-C), and such phenotype was abrogated in S. Tm isogenic $\Delta d c u A$ (Fig. 3B) and $\Delta \operatorname{tar}$ (Fig. 3C) isogenic mutants. S. Tm $\Delta d c u A$ and $\Delta$ tar mutants were able to grow to similar levels as wild-type strains when glucose was given as a carbon source (data not shown), suggesting that their inability to grow under glycerol and aspartate conditions was not due to an overall growth defect. Taken together, our results show that transport of exogenous aspartate and chemotaxis towards this amino acid support respiration-dependent growth of pathogenic Enterobacteriaceae in vitro under anaerobic conditions.

Our in vitro results led us to investigate whether transport of exogenous aspartate and chemotaxis towards this amino acid enable pathogenic Enterobacteriaceae to take advantage of the increased levels of aspartate in the inflamed gut (Fig. 1A-B). To do so, we intragastrically infected CBA/J mice with a 1:1 ratio of wild-type $S$. Tm and an isogenic $\Delta d c u A$ mutant or a 1:1 ratio of wild-type S. Tm and an isogenic $\Delta t a r$ mutant and determined the competitive index between strains at day 10 post-infection. Wild-type $S$. Tm was able to significantly outcompete the $\Delta d u c A$ mutant as well as the $\Delta$ tar mutant (Fig. 3D) in fecal samples from infected mice. Such increased competitive advantage of wild-type $S$. Tm over the $\Delta d c u A$ and $\Delta t a r$ mutants was associated with the presence of marked intestinal inflammation (Fig. 3E), suggesting that the chemotaxis towards and transport of exogenous aspartate promotes the expansion of pathogenic Enterobacteriaceae during infectious colitis. 
Pathogenic Enterobacteriaceae have evolved to use fumarate reductase, encoded by frdABCD

genes, to grow under anaerobic conditions in vitro and in vivo (Iverson et al., 1999; Jones et al., 2007; Mercado-Lubo et al., 2008; Paiva et al., 2009). Interestingly, the S. Tm and pks+ E. coli SP15 genomes encode the aspA gene (aspartate ammonia-lyase), which enable the conversion of the amino acid aspartate into fumarate (Nguyen et al., 2020; Nógrády et al., 2003) (Fig. S2A). Indeed, anaerobic growth of S. Tm in the presence of aspartate alone or in combination with glycerol induced expression of one of the genes in the fumarate reductase operon, $f r d B$ (Fig. 3A). To investigate whether aspartate utilization conferred a fitness advantage to pathogenic Enterobacteriaceae by supporting fumarate respiration, we determined the anaerobic growth of $S$. Tm wild-type and $\triangle \operatorname{frd} A B C D(\triangle \mathrm{frd})$ isogenic mutants as well as $E$. coli SP15 wild-type and $\Delta$ frd isogenic mutants in minimal medium supplemented or not with $40 \mathrm{mM}$ glycerol (carbon source) and $30 \mathrm{mM}$ aspartate (Fig. 4A-B). Aspartate alone did not promote growth of S. Tm (Fig. 4A) or E. coli SP15 strains (Fig. 4B) in minimal medium. However, S. Tm and E. coli SP15 were able to grow in minimal medium supplemented with glycerol and aspartate, and such phenotype was abolished in S. Tm and E. coli $\Delta$ frd isogenic mutants (Fig. 4A and 4B). S. Tm and $E$. coli $\Delta$ frd mutants were able to grow to similar levels as wild-type strains when glucose was given as a carbon source (data not shown), suggesting that their inability to grow under glycerol and aspartate conditions was not due to an overall growth defect. These results confirm previous reports (Nguyen et al., 2020; Schubert et al., 2021) that pathogenic Enterobacteriaceae utilize aspartate as a source of fumarate to support respiration-dependent growth under in vitro anaerobic conditions.

Our results (Fig. 4A-B) and previous reports (Nguyen et al., 2020; Schubert et al., 2021) demonstrate that pathogenic Enterobacteriaceae can use aspartate to support fumarate respiration in vitro. However, whether increased aspartate availability supports pathogenic Enterobacteriaceae expansion in the inflamed gut in a fumarate respiration-dependent manner remained unknown. To address this gap in knowledge, we intragastrically infected CBA/J mice with a 1:1 ratio of wild-type $S$. Tm and an isogenic $\triangle a s p A$ mutant or a $1: 1$ ratio of $\Delta$ frd and isogenic $\Delta$ frd $\Delta a s p A$ mutants and 
determined the competitive index between strains at day 10 post-infection. Wild-type $S$. Tm was able

to significantly outcompete the $\triangle a s p A$ mutant (Fig. 4C) when intestinal inflammation is established (Fig.

4D). The aspartate-dependent $S$. Tm growth advantage over an aspartate-deficient mutant was

abrogated in mice colonized with $\Delta$ frd and isogenic $\Delta$ frd $\Delta a s p A$ mutants (Fig. 4C), suggesting that

aspartate fuels $S$. Tm fumarate respiration in the inflamed gut.

Next, we sought to investigate the role of chemotaxis towards and transport of exogenous aspartate in supporting fumarate-dependent S. Tm respiration during colitis. We intragastrically infected CBA/J mice with a 1:1 ratio of wild-type $S$. Tm and an isogenic $\Delta \operatorname{tar}$ mutant or $\Delta$ frd and isogenic $\Delta$ frd $\Delta \operatorname{tar}$ (Fig. S2B) or 1:1 ratio of wild-type S. Tm and an isogenic $\Delta d c u A$ mutant $\Delta$ frd and isogenic $\Delta$ frd $\triangle d c u A$ (Fig. S2C) mutants and assessed the competitive index between strains at day 10 post-infection. Wild-type S. Tm was able to significantly outcompete the $\Delta \operatorname{tar}$ mutant (Fig. 3D and S2B) and the $\Delta d c u A$ (Fig. 3D and S2C) mutant during colitis. This growth advantage was abolished in mice colonized with $\Delta f r d$ and isogenic $\Delta$ frd $\Delta \operatorname{tar}$ mutant (Fig. S2C) or in mice colonized with $\Delta$ frd and isogenic $\Delta$ frd $\Delta d u c A$ mutant. These results revealed the need for $S$. Tm to perform chemotaxis and gain access to exogenous aspartate to support fumarate respiration during infectious colitis.

To confirm that $S$. Tm $\Delta$ frd mutant is defective in colonizing the intestinal lumen during colitis, we repeated the experiment by performing single infections in the CBA/J model with wild-type $S$. Tm and isogenic $\Delta$ frd mutant. We determined intestinal colonization by $S$. Tm strains at day three, seven and ten post-infection. Wild-type S. Tm growth in the intestinal lumen significantly increased as disease progressed, reaching higher levels at day seven and ten post-infection (Fig. 4E). However, S. Tm $\Delta$ frd was defective in colonizing the intestinal lumen (Fig. 4E) and in inducing colitis (Fig 4D), suggesting that fumarate respiration is necessary for $S$. Tm to thrive in the gut and induce intestinal inflammation. Importantly, the inability of $S$. Tm $\Delta$ frd mutant to cause intestinal inflammation was not due to an invasion defect, as the $S$. Tm $\Delta$ frd strain was able to invade intestinal epithelial cells to similar levels as wild-type S. Tm in vitro (Fig. S2D). The concentration of aspartate was measured in the feces of mice infected with wild-type or $\Delta$ frd and a significant difference in fecal aspartate levels was observed (Fig. 
$064 F$ ) indicating that the decreased ability of $S$. Tm $\Delta$ frd to colonize the intestinal lumen in our infectious

07 colitis model could be due to decreased levels of aspartate in $\Delta$ frd-infected mice. To address this

08 concern, we repeated the competitive infection experiment described in Fig. $\mathbf{4 C}$ and increased

09 intestinal concentrations of aspartate in $\Delta$ frd-infected mice by providing aspartate $(0.4 \%)$ in the drinking

10 water throughout the experiment (Fig. 4G-H). Aspartate supplementation did not increase the ability of

11 the fumarate. respiration-deficient $S$. Tm strain to outcompete an isogenic $\triangle a s p A$ mutant at ten days

12 post-infection (Fig. 4G), despite the increased aspartate levels in the intestinal lumen of $S$. Tm $\Delta$ frd-

13 infected mice that received aspartate supplementation (Fig. $4 \mathbf{H}$ ). Taken together, our findings suggest

14 that inflammation-mediated increase in aspartate levels is necessary to support fumarate-dependent

15 intestinal expansion of pathogenic Enterobacteriaceae in the inflamed gut.

\section{Dietary aspartate is not the main source of this amino acid during intestinal inflammation}

Previous work suggests that dietary aspartate fuels aspartate-dependent fumarate respiration during early intestinal Enterobacteriaceae infection, before the onset of inflammation (Nguyen et al., 2020; Schubert et al., 2021). However, the source of aspartate (Fig. 1A and B) in the inflamed gut is unknown. To assess whether diet-derived aspartate facilitates aspA-dependent $S$. Tm expansion during intestinal inflammation, we determined the ability of wild-type $S$. Tm to outcompete an isogenic $\triangle a s p A$ mutant in the intestines of CBA/J mice fed a control (Asp+) and an aspartate-free (Asp-) diet (Fig. 5A-C). To our surprise, wild-type $S$. Tm had a significant growth advantage over the $\triangle$ aspA mutant in both Asp+ and Asp- diet groups (Fig. 5A). This phenotype was accompanied by increased aspartate levels in the intestinal lumen of mice fed either diet (Fig. 5B) as well as comparable intestinal inflammation in both groups (Fig. 5C). Similar results were obtained in DSS-treated mice infected with wild-type E. coli SP15 and an isogenic $\triangle$ aspA mutant (Fig. 5D-F). Our findings demonstrate that dietary 
aspartate is not the main source of this amino acid during infectious and noninfectious colitis and does

not contribute to aspartate-dependent Enterobacteriaceae expansion during intestinal inflammation.

32

\section{Microbiota-derived aspartate fuels pathogenic Enterobacteriaceae expansion in the inflamed}

gut

Next, we sought to assess whether the host or the gut microbiota were the source of aspartate in the inflamed gut. To test whether the host response is the major source of aspartate during intestinal inflammation, we measured aspartate levels in fecal contents of germ-free mouse models of infectious and noninfectious colitis. We used germ-free Swiss-Webster (SW) mice, a mouse strain that is susceptible to S. Tm-induced gastroenteritis (Gillis et al., 2018; Shelton et al., 2021), and DSS-induced colitis (Hughes et al., 2017). Importantly, mock-treated germ-free SW mice had very low aspartate levels in their feces (Fig. S3A). To induced infectious colitis in our germ-free SW mouse model, we intragastrically infected mice with wild-type $S$. Tm for three days. We were unable to carry the experiment beyond a three-day time-point as germ-free mice are highly susceptible to $S$. Tm induced intestinal inflammation (Shelton et al., 2021). To induce colitis independently of a pathogen (noninfectious colitis), we treated germ-free SW mice with $2.5 \%$ dextran sodium sulfate (DSS) in the drinking water for seven days. Interestingly, we observed no increase in aspartate levels in fecal samples from S. Tm-infected gem-free mice (Fig. S3A) and DSS-treated germ-free mice (Fig. S3A) when compared to mock-treated animals, despite the development of intestinal inflammation (Fig. S3B). These results provide the initial evidence that the host inflammatory response alone is not the main contributor to the increased levels of luminal aspartate during colitis.

To determine whether pathogenic Enterobacteriaceae rely on aspA-dependent aspartate utilization in vivo in the absence of a resident microbiota, we infected germ-free SW mice with 1:1 ratio of wildtype S. Tm and $\triangle a s p A$ mutant and assessed the competitive index between strains three days post infection. S. Tm infected germ-free mice developed intestinal inflammation comparable to that observed 
56 in conventional mice (Fig. S3B). Wild-type S. Tm was unable to outcompete the isogenic $\triangle a s p A$ mutant

in this model (Fig. 6A). Similar results were obtained in DSS-treated germ-free SW mice infected with

wild-type E. coli SP15 and an isogenic $\triangle a s p A$ mutant (Fig. 6C). Our findings suggest that host-derived aspartate does not support the growth of pathogenic Enterobacteriaceae during colitis, raising the possibility that the resident microbiota is supporting aspartate-dependent pathogen-expansion during intestinal inflammation.

To further explore the hypothesis that the resident microbiota is the major source of aspartate during intestinal inflammation, we pre-colonized germ-free SW mice with commensal microbes representing the most abundant commensal bacteria classes in the mouse gut (Fig. S3C) (Winter et al., 2010) and repeated the competitive infection experiments described above. Interestingly, the increased aspartate levels as well as the ability of wild-type $S$. Tm to outcompete the $\Delta a s p A$ mutant were restored in the intestinal lumen of germ-free mice pre-colonized with constituents from the classes

Bacteroidia (Bacteroides caecimuris) or Clostridia (a combination of Clostridium clostridioforme, Clostridium innocuum, Clostridioides mangenotti, Clostridium cochlearium and Clostridium sporogenes), but not when mice were pre-colonized with constituents of the class Bacilli (Lactobacillus reuteri). Importantly, differences in the competitive advantage between wild-type S. Tm and an $\triangle$ aspA mutant were not due to differences in intestinal inflammation between groups (Fig. 6C). Similar results were obtained in DSS-treated germ-free SW mice pre-colonized with members of the microbiota and infected with wild-type E. coli SP15 and an isogenic $\triangle a s p A$ mutant (Fig. 6D-F). Noninfectious intestinal 
The gut microbiota occupies major nutrient niches to limit pathogen expansion in the gastrointestinal tract (colonization resistance) (Shealy et al., 2021). In particular, commensal microbes provide colonization resistance by sequestering amino acids (Caballero-Flores et al., 2020), reducing the pool of a key nutrient source for pathogenic Enterobacteriaceae expansion in the intestinal lumen (Kitamoto et al., 2020; Nguyen et al., 2020; Schubert et al., 2021). Thus, enteric pathogens must develop strategies to alter the gut environment in a way that allows for them to gain access to amino acids that are necessary for successful intestinal colonization (Nguyen et al., 2020; Schubert et al., 2021). In this study we report that intestinal inflammation causes increased levels of the amino acid aspartate in the intestinal lumen, in a microbiota-dependent manner. Our data show that $S$. Tm and $p k s+E$. coli (E. coli SP15) can use this new source of exogenous aspartate to support fumaratedependent anaerobic respiration in the inflamed gut. This leads to an advantage in vivo as $S$. Tm and E. coli SP15 strains that can transport aspartate and perform aspartate-dependent fumarate respiration outcompete isogenic strains that cannot utilize this amino acid. Collectively, we describe a previously unexplored mechanism by which pathogenic Enterobacteriaceae exploit the gut microbiota to acquire the amino acid aspartate and support aspartate-dependent anaerobic respiration in the inflamed gut (Fig. S4).

Recent reports identify dietary aspartate as a potential source of fumarate-dependent respiration during early intestinal Enterobacteriaceae infection, before the onset of inflammation (Nguyen et al., 2020; Schubert et al., 2021). However, in this study we show that dietary aspartate does not contribute to S. Tm and E. coli SP15 expansion in the inflamed gut. We identified the gut microbiota, especially members of the class Bacteroidia and Clostridia, as the major source of aspartate during intestinal inflammation. It remains unclear how inflammation can induce the release of amino acids by the gut microbiota. One possibility is that the innate immune response elicited by $S$. Tm infection or noninfectious colitis stimulates the production of toxic reactive oxygen species (ROS) and antimicrobial peptides, which can induce bacterial lysis of microbiota constituents (Li et al., 2020; Lin and Zhang, 
08 2017; Takiishi et al., 2017). Alternatively, the introduction of oxygen as a function of inflammation

09 (Rivera-Chávez et al., 2016) may alter key metabolic pathways leading to inadvertent secretion of

10 aspartate by the microbiota in response to an adaptation to the loss of intestinal anaerobiosis (Lin and

11 Zhang, 2017; Takiishi et al., 2017). Understanding the mechanism of amino acid release by the gut

12 microbiota as a consequence of the host inflammatory response may have significant implications in

13 the pathogenesis of infectious and noninfectious colitis and will be an important area of future research.

Commensal Enterobacteriaceae play a crucial role in colonization resistance against $S$. Tm and

other pathogenic members of this family (Brugiroux et al., 2016; Litvak et al., 2019; Velazquez et al.,

2019; Wotzka et al., 2019). In particular, commensal Enterobacteriaceae compete for carbon sources

(Eberl et al., 2021) and electron acceptors generated by the host response (Litvak et al., 2019;

Velazquez et al., 2019) during early infection. However, the metabolic interactions between commensal

and pathogenic Enterobacteriaceae during the late stages of colitis (once intestinal inflammation is

established) remain unclear. The gene encoding aspartate ammonia-lyase (aspA) is conserved

amongst commensal E. coli species and non-pathogenic members of the Enterobacteriaceae family

can perform aspartate-dependent fumarate respiration (Schubert et al., 2021) (data not shown). Such

findings suggest that not only pathogenic Enterobacteriaceae but also commensal species belonging

to this family may have access to this novel source of electron acceptors to expand in the inflamed gut.

Thus, the mechanisms used by $S$. Tm to outcompete commensal Enterobacteriaceae aspartate utilization and gain access to this key resource remain to be elucidated.

In conclusion, our findings provide a fundamental advance in understanding how pathogenic Enterobacteriaceae have evolved to utilize microbiota-derived metabolites to thrive in the inflamed gut. The emerging picture is that enteric pathogens rely on microbiota-derived amino acids as a source of electron acceptors for growth via anaerobic respiration during intestinal inflammation. Our findings may aid in the development of novel treatment strategies focused on pathogen metabolic adaptations for infectious and noninfectious gastroenteritis. 


\section{Acknowledgments}

W.Y. was supported by the Basic Science Research Program through the National Research

Foundation of Korea (N.R.F.) by the Ministry of Education 2020R1A6A3A03037326. N.G.S. was

supported by NIH T32 Training Grant T32ES007028-46 and GT15104 from the Howard Hughes

Medical Institute through the James H. Gilliam Fellowships for Advanced Study program. C.D.S. was

\section{Author contributions}

W.Y., J.K.Z., and M.X.B. designed and conceived the study. W.Y., J.K.Z., N.G.S., T.P.T., J.D.T., C.D.S., N.J.F., and E.E.O. performed all experiments. All authors contributed to the data analysis and preparation of the manuscript. M.X.B. secured funding for the study.

\section{Declaration of interests}

The authors declare no conflict of interest.

\section{FIGURE LEGENDS}

Figure 1. Figure 1. Aspartate utilization via aspA fuels pathogenic Enterobacteriaceae expansion during colitis. (A) Female CBA/J mice were infected intragastrically with $10^{9} \mathrm{CFU}$ of Salmonella enterica serovar Typhimurium (S. Tm) for ten days. Fecal aspartate levels were measured 
at day ten post-infection. (B) Female C57BL/6J mice were treated with 2.5\% Dextran Sodium Sulfate

(DSS) in their drinking water for seven days. Fecal aspartate levels were determined seven days after

beginning DSS. (C-D) Wild-type S. Tm (C) and Escherichia coli SP15 (D) and isogenic $\triangle a s p A$ mutants

Figure 2. Intestinal inflammation is required for aspartate utilization by $S$. $T m$ in the gut. (A) Female CBA/J mice were intragastrically infected with $10^{9} \mathrm{CFU}$ of a 1:1 ratio of wild-type $S$. Tm (WT) and isogenic $\triangle a s p A$ mutant or a 1:1 ratio of $S$. Tm $\triangle i n v A \Delta s p i B$ and $\triangle i n v A \Delta s p i B \Delta a s p A$ isogenic mutant for ten days. Competitive index in fecal samples was determined at day one, three, seven and ten postinfection. (B) Combined histopathology score of pathological lesions in the cecum of mice from (B) at ten days post-infection ( $n=5)$. (C) Fecal aspartate levels from mice in (A) measured at day ten post- 
infection. (D) Female CBA/J mice were intragastrically infected with $10^{9} \mathrm{CFU}$ of a $1: 1$ ratio of $S$. Tm

$\Delta i n v A \Delta s p i B$ and $\triangle i n v A \Delta s p i B \Delta a s p A$ isogenic mutant for ten days. A subset of mice received L-

aspartate $(0.4 \%)$ supplementation in their drinking water for the duration of the experiment (Aspartate

+). (E) Combined histopathology score of pathological lesions in the cecum of mice from (B) at ten days post-infection $(n=5)$. (F) Fecal aspartate levels from mice in $(A)$ measured at day ten post-infection.

Each dot represents data from one animal (biological replicate). Bars represent mean \pm SEM. The

boxes in the whisker plot represent the first to third quartiles, and the mean value of the gross pathology scores is indicated by a line. ${ }^{*}, p<0.05 ;{ }^{* *}, p<0.01 ;{ }^{* * *}, p<0.001$.

Figure 3. Transport of exogenous aspartate and chemotaxis towards this amino acid support $S$. Tm expansion in the inflamed gut. (A) Wild-type S. Tm was grown in NCE minimal media supplemented or not with glycerol $(40 \mathrm{mM})$ and L-aspartate $(30 \mathrm{mM})$ under anaerobic conditions. Gene expression analysis of the aspartate transport and utilization genes $\operatorname{tar}, \operatorname{asp} A, d c u A$ and $\operatorname{frd} B$ was performed by qRT-PCR at four hours post-inoculation, and target gene transcription of each sample was normalized to $16 \mathrm{~S}$ rRNA mRNA levels. (B-C) Wild-type $S$. Tm and isogenic $\Delta d c u A(B)$ and $\Delta \operatorname{tar}(\mathrm{C})$ mutants were grown in NCE minimal media supplemented or not with glycerol (40 mM) and L-aspartate (30 mM) for 18 hours under anaerobic conditions. (D) Female CBA/J mice were intragastrically infected with $10^{9} \mathrm{CFU}$ of a 1:1 ratio of wild-type $S$. Tm (WT) and isogenic $\triangle d c u A$ mutant or a 1:1 ratio of wildtype S. Tm (WT) and isogenic $\Delta$ tar mutant for ten days. Competitive index in fecal samples was determined at day ten post-infection. (E) Combined histopathology score of pathological lesions in the cecum of mice from (D) at ten days post-infection $(n=4)$. Bars represent mean \pm SEM. The boxes in the whisker plot represent the first to third quartiles, and the mean value of the gross pathology scores is indicated by a line. ${ }^{*}, p<0.05 ;{ }^{* *}, p<0.01 ;{ }^{* * *}, p<0.001$. 
11 Figure 4. Increased aspartate availability supports fumarate respiration by pathogenic

12 Enterobacteriaceae in the inflamed gut. (A-B) Wild-type S. Tm (A) and Escherichia coli SP15 (B)

13 and isogenic $\Delta$ frd mutants were grown in NCE minimal media supplemented or not with glycerol (40

$14 \mathrm{mM})$ and L-aspartate $(30 \mathrm{mM})$ for 18 hours under anaerobic conditions. (C) Female CBA/J mice were

15 intragastrically infected with $10^{9} \mathrm{CFU}$ of a $1: 1$ ratio of wild-type $S$. Tm (WT) and isogenic $\triangle$ aspA mutant

or $S . T m \Delta$ frd and isogenic $\Delta$ frd $\Delta a s p A$ mutant for ten days. Competitive index in fecal samples was

determined at day ten post-infection. (D) Combined histopathology score of pathological lesions in the

cecum of mice from $(C)$ at ten days post-infection $(n=4)$. (E) Female CBA/J mice were intragastrically

infected with $10^{9} \mathrm{CFU}$ of wild-type $S$. Tm (WT) or isogenic $\Delta$ frd mutant for ten days. Bacterial numbers

in fecal samples were determined at day ten post-infection. $(F)$ Fecal aspartate levels from mice in $(E)$

measured at day ten post-infection. (G) Female CBA/J mice were intragastrically infected with $10^{9} \mathrm{CFU}$ of a 1:1 ratio of $S$. Tm $\Delta$ frd and $\Delta$ frd $\triangle a s p A$ isogenic mutant for ten days. A subset of mice received Laspartate $(0.4 \%)$ supplementation in their drinking water for the duration of the experiment (Aspartate +). (H) Fecal aspartate levels from mice in (E) measured at day ten post-infection. For in vitro experiments, each dot represents one biological replicate (average of triplicate technical replicate per biological replicate). For mouse experiments, each dot represents data from one animal (biological replicate). Bars represent mean \pm SEM. The boxes in the whisker plot represent the first to third quartiles, and the mean value of the gross pathology scores is indicated by a line. ${ }^{* *}, p<0.01 ;{ }^{* *}, p<$ 0.001. See also Figure S2.

Figure 5. Dietary aspartate is not a major source of aspartate for pathogenic Enterobacteriaceae in the inflamed gut. (A) Female CBA/J mice received a control (Asp +) or an aspartate-free diet (Asp -) for the duration of the experiment. Mice were intragastrically infected with $10^{9} \mathrm{CFU}$ of a 1:1 ratio of wild-type S. Tm (WT) and isogenic $\triangle a s p A$ for ten days. Competitive index in fecal samples was determined at day ten post-infection. (B) Fecal aspartate levels from mice in (A) measured at day ten 
post-infection. (C) Combined histopathology score of pathological lesions in the cecum of mice from

(A) at ten days post-infection ( $n=5)$. (D) Female C57BI6/J mice received a control (Asp + ) or an

aspartate-free diet (Asp -) for the duration of the experiment. Female C57BL/6J mice were

intragastrically infected with $10^{9} \mathrm{CFU}$ of a 1:1 ratio of wild-type E. coli SP15 (WT) and isogenic $\triangle$ aspA

mutant. One day after infection mice were treated with $2.5 \%$ Dextran Sodium Sulfate (DSS) in their

drinking water for seven days. Competitive index in fecal samples was determined at day eight post-

infection. (E) Fecal aspartate levels from mice in (D) measured at day eight post-infection.

\section{Figure 6. Microbiota-derived aspartate supports pathogenic Enterobacteriaceae expansion in}

the inflamed gut. (A-C) Female and male Swiss-Wester (SW) germ-free mice were pre-colonized with individual species or a combination of gut commensal microbes for five days. Bact: Bacteroides caecimuris; Clost: a combination of Blautia coccoides, Clostridium cochlearium and Clostidium sporogenes; Lact: Lactobacillus reuteri. After five days, mice were intragastrically infected with $10^{9} \mathrm{CFU}$ of a 1:1 ratio of wild-type $S$. Tm (WT) and isogenic $\Delta a s p A$ for three days. (A) Fecal aspartate levels measured at three days after $S$. Tm infection. (B) Competitive index of $S$. Tm strains in fecal samples was determined at day three post-infection. (C) Combined histopathology score of pathological lesions in the cecum of mice from (B) at three days post-infection (n=5-10). (D-F) Female and male SW germfree mice were pre-colonized with individual species or a combination of gut commensal microbes for five days. Bact: Bacteroides caecimuris; Clost: a combination of Blautia coccoides, Clostridium cochlearium and Clostidium sporogenes; Lact: Lactobacillus reuteri. After five days, mice were intragastrically infected with $10^{9} \mathrm{CFU}$ of a 1:1 ratio of wild-type E. coli SP15 (WT) and isogenic $\triangle a s p A$ 
61 mutant. One day after infection mice were treated with $2.5 \%$ Dextran Sodium Sulfate (DSS) in their

62 drinking water for seven days. Competitive index in fecal samples was determined at day eight post-

63 infection(D) Fecal aspartate levels measured at seven days after DSS treatment. (E) Competitive index

64 of $E$. coli strains in fecal samples was determined at day eight post-infection. (F) Combined

65 histopathology score of pathological lesions in the cecum of mice from $(E)$ at eight days post-infection

$66(n=4)$. Each dot represents data from one animal (biological replicate). Bars represent mean \pm SEM.

67 The boxes in the whisker plot represent the first to third quartiles, and the mean value of the gross

68 pathology scores is indicated by a line. ${ }^{*}, p<0.05 ;{ }^{* *}, p<0.01$. See also Figure S3.

\section{MATERIAL AND METHODS}

\section{RESOURCES AVAILABILITY}

\section{Lead contact}

Further information and requests for resources and reagents should be directed to and will be fulfilled by the lead contact, Mariana X. Byndloss (mariana.x.byndloss@vumc.org).

\section{Materials availability}

All unique reagents generated in this study are available from the lead contact without restriction.

\section{Data and code availability}

Data reported in this paper will be shared by the lead contact upon request. This paper does not report original code. Any additional information required to reanalyze the data reported in this paper is available from the lead contact upon request.

\section{EXPERIMENTAL MODEL AND SUBJECT DETAILS}

\section{Mouse husbandry}


All animal experiments in this study were approved by the Institutional Animal Care and Use

Committee at the Vanderbilt University Medical Center. Female CBA and C57BL/6 mice were obtained

from the Jackson Laboratory. Germ-Free Swiss Webster (SW) mice were bred in house and maintained

in specific pathogen-free facilities at Vanderbilt University Medical Center. A subset of germ-free mice

was colonized with a defined microbiota to obtain the SW mice used in this study. The age at the

beginning of the experiment was 6-7 weeks old for all CBA, C57BL/6 and SW mice. Conventional mice

were housed in individually ventilated cages with ad libitum access to water and chow (Envigo Global

$16 \%$ Protein Rodent Diet). Germ-free SW mice were housed in sterile positive pressure cages (Allentown) with ad libitum access to sterile water and chow.

For the germ-free SW mice, unless indicated otherwise in the figure legend, both male and

\section{Bacterial strains}

S. Typhimurium IR715 and E. coli SP15 strains were routinely grown aerobically at $37^{\circ} \mathrm{C}$ in LB broth (10 g/L tryptone, $5 \mathrm{~g} / \mathrm{L}$ yeast extract, $10 \mathrm{~g} / \mathrm{L}$ sodium chloride) or on LB agar plates ( $10 \mathrm{~g} / \mathrm{L}$ tryptone, $5 \mathrm{~g} / \mathrm{L}$ yeast extract, $10 \mathrm{~g} / \mathrm{L}$ sodium chloride, $15 \mathrm{~g} / \mathrm{L}$ agar). For growth under anaerobic conditions, Nocarbon-E (NCE) minimal medium (28 mM KH $\mathrm{KHO}_{4}, 28 \mathrm{mM} \quad \mathrm{K}_{2} \mathrm{HPO}_{4} \cdot 3 \mathrm{H}_{2} \mathrm{O}$ and $16 \mathrm{mM}$ $\mathrm{NaNH}_{4} \mathrm{HPO}_{4} \cdot 4 \mathrm{H}_{2} \mathrm{O}$ ) supplemented with $1 \mathrm{mM} \mathrm{MgSO}_{4}, 0.1 \%$ Casamino acids and $1 \%$ Vitamin and Trace mineral solutions (American Type Culture Collection) was used. As a sole carbon source, glycerol (40 
$\mathrm{mM}$ ) was added to the bacterial culture, and L-aspartate ( $30 \mathrm{mM})$ was also used as a source of fumarate

14 for anaerobic fumarate respiration. All S. Typhimurium IR715 and E. coli SP15 strains were incubated 15 at $37^{\circ} \mathrm{C}$ in an anaerobic chamber $(0 \%$ oxygen). When appropriate, agar plates and media were supplemented with $30 \mu \mathrm{g} / \mathrm{mL}$ chloramphenicol $(\mathrm{Cm}), 100 \mu \mathrm{g} / \mathrm{mL}$ carbenicillin (Carb), $50 \mu \mathrm{g} / \mathrm{mL}$

Construction of Salmonella enterica serovar Typhimurium mutants

For the S. Typhimurium IR715 $\triangle \operatorname{tar}, \triangle a s p A, \triangle d c u A$ or $\triangle$ frdABCD deletion mutants, the upstream and downstream regions of approximately $0.5 \mathrm{~kb}$ flanking the $\operatorname{tar}$, aspA, $d c u A$ or $\operatorname{frd} A B C D$ genes were amplified by PCR using primers IR715-tar-del-F1/IR715-tar-del-R1 and IR715-tar-del-F2/ IR715-tardel-R2, IR715-aspA-del-F1/IR715-aspA-del-R1 and IR715-aspA-del-F2/IR715-aspA-del-R2, IR715dcuA-del-F1/IR715-dcuA-del-R1 and IR715-dcuA-del-F2/IR715-dcuA-del-R2 or IR715-frdABCD-delF1/IR715-frdABCD-del-R1 and IR715-frdABCD-del-F2/IR715-frdABCD-del-R2 from the $S$. Typhimurium IR715 wild-type genome. The pRDH10 suicide plasmid was digested with Sall and 
assembled with the fragments of each gene using the Gibson Assembly Master Mix (NEB) to form

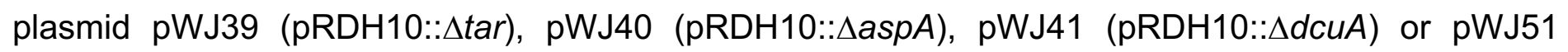

(pRDH10:: $\triangle$ frdABCD).

$\lambda$ pir and conjugated into S. Typhimurium IR715 wild-type. Clones that had integrated the suicide plasmid were subjected to sucrose counter-selection and a colony that was sucrose resistant and $\mathrm{Cm}^{\mathrm{s}}$ was verified by PCR to be $S$. Typhimurium IR715 $\triangle \operatorname{tar}, \triangle a s p A, \triangle d c u A$ or $\triangle$ frdABCD deletion mutants.

Recombinant plasmids pWJ39, pWJ40 or pWJ41 were transformed into E. coli S17-1 $\lambda$ pir and conjugated into S. Typhimurium IR715 $\triangle$ frdABCD mutant (WJ28) using E. coli S17-1 $\lambda$ pir as the donor strain. Clones that had integrated the suicide plasmid were subjected to sucrose counter-selection and a colony that was sucrose resistant and $\mathrm{Cm}^{\mathrm{S}}$ was verified by PCR to be $S$. Typhimurium IR715 $\triangle$ frdABCD $\triangle \operatorname{tar}, \triangle$ frdABCD $\triangle a s p A$ or $\triangle$ frdABCD $\triangle d c u A$ mutants.

Recombinant plasmids pWJ39, pWJ40, pWJ41 or pWJ51 were transformed into E. coli S17-1 $\lambda$ pir and conjugated into S. Typhimurium IR715 $\Delta$ invA $\Delta$ spiB mutant (SPN487) using E. coli S17-1 $\lambda$ pir as the donor strain. Clones that had integrated the suicide plasmid were subjected to sucrose counterselection and a colony that was sucrose resistant and $\mathrm{Cm}^{s}$ was verified by PCR to be $S$. Typhimurium IR715 $\Delta i n v A \Delta s p i B \Delta \operatorname{tar}, \Delta i n v A \Delta s p i B \Delta a s p A, \triangle i n v A \Delta s p i B \triangle d c u A$ or $\triangle i n v A \Delta$ spiB $\triangle$ frd $A B C D$ mutants. The $\Delta p h o N:: \operatorname{Tn} 10 d-\mathrm{Cm}^{\mathrm{R}}$ and $\Delta p h o N:: \mathrm{Km}^{\mathrm{R}}$ mutation were transduced by phage $\mathrm{P} 22 \mathrm{HT}$ int-105 (Schmieger, 1972) from FF176 and AJB715 respectively. Primers and plasmids used to construct the bacterial strains are listed in Table S1 and S2 respectively.

\section{Construction of Escherichia coli SP15 mutants}

To delete aspA or frdABCD from the E. coli SP15 parent strain, lambda red recombination was used. The $\mathrm{Cm}^{\mathrm{R}}$ cassette was amplified from pKD3 using the SP15-aspA-del-F1/SP15-aspA-del-R1 primers and the $\mathrm{Kan}^{\mathrm{R}}$ cassette was amplified from pKD13 using the SP15-frdABCD-del-F1/SP15- 
frdABCD-del-R1 primers. The resulting PCR product was integrated into the aspA or frdABCD region

in a wild-type E. coli SP15 strain containing the plasmid pKD46, followed by the selection of

$\triangle a s p A:: \mathrm{Cm}^{\mathrm{R}}$ or $\triangle f r d A B C D:: \mathrm{Kan}^{\mathrm{R}}$ mutants. The $\mathrm{Cm}^{\mathrm{R}}$ or $\mathrm{Kan}^{\mathrm{R}}$ cassette was removed using the plasmid pCP20 (Datsenko and Wanner, 2000). Primers and plasmids used to construct the bacterial strains are listed in Table S1 and S2 respectively.

\section{In vitro bacterial growth assays}

Growth assays were performed in No-carbon-E (NCE) minimal medium (28 $\mathrm{mM} \mathrm{KH}_{2} \mathrm{PO}_{4}, 28 \mathrm{mM}$ $\mathrm{K}_{2} \mathrm{HPO}_{4} \cdot 3 \mathrm{H}_{2} \mathrm{O}$ and $16 \mathrm{mM} \mathrm{NaNH}_{4} \mathrm{HPO}_{4} \cdot 4 \mathrm{H}_{2} \mathrm{O}$ ) supplemented with $1 \mathrm{mM} \mathrm{MgSO}_{4}, 0.1 \%$ Casamino acids and 1\% Vitamin and Trace mineral solutions (American Type Culture Collection) in the presence or absence of glycerol $(40 \mathrm{mM})$ as a sole carbon source and/or L-aspartate (30 mM) as a source of fumarate. For anaerobic growth experiments, media was placed in the anaerobic chamber $48 \mathrm{~h}$ prior to inoculation. Overnight aerobic cultures of S. Tm or E. coli strains were harvested, washed in PBS, and resuspended in NCE media. Wild-type S. Tm or E. coli was then added to anaerobic media containing carbon source (40 mM glycerol) and/or a source of fumarate (30 mM L-aspartate), which is used as an electron acceptor, at a final concentration of $1 \times 10^{4} \mathrm{CFU} / \mathrm{mL}$. Bacterial growth was determined after $18 \mathrm{~h}$ by spreading serial ten-fold dilutions onto LB agar plates containing the appropriate antibiotics.

To measure anaerobic growth of wild-type and mutant strains of S. Tm and E. coli with glycerol and/or L-aspartate, overnight cultures of each strain were harvested, washed in PBS, and resuspended in NCE media. In a 96 well plate, strains were added to NCE media containing $40 \mathrm{mM}$ glycerol or 30 $\mathrm{mM} \mathrm{L-aspartate,} \mathrm{or} \mathrm{a} \mathrm{combination} \mathrm{of} \mathrm{both} \mathrm{at} \mathrm{a} \mathrm{final} O D_{600}=0.1 . \mathrm{OD}_{600}$ was measured for $24 \mathrm{~h}$ using the Epoch 2 plate reader (Bio-Tek). In vitro bacterial growth assays were performed in triplicate with different colonies. 


\section{Bacterial RNA isolation and quantitative real-time PCR}

89 To determine bacterial gene expression in vitro, NCE minimal medium (28 mM $\mathrm{KH}_{2} \mathrm{PO}_{4}, 28 \mathrm{mM}^{2}$

$90 \mathrm{~K}_{2} \mathrm{HPO}_{4} \cdot 3 \mathrm{H}_{2} \mathrm{O}$ and $16 \mathrm{mM} \mathrm{NaNH}_{4} \mathrm{HPO}_{4} \cdot 4 \mathrm{H}_{2} \mathrm{O}$ ) supplemented with $1 \mathrm{mM} \mathrm{MgSO}, 0.1 \%$ Casamino acids

91 and 1\% Vitamin and Trace mineral solutions (American Type Culture Collection) was inoculated with

92 S. Typhimurium IR715 strains and cultured at $37^{\circ} \mathrm{C}$ under anaerobic condition. Glycerol (40 mM) was

93 provided as a sole carbon/energy source and L-aspartate (30 $\mathrm{mM})$ was added as a source of fumarate

94 for anaerobic fumarate respiration. Total RNA was extracted from the bacterial cells grown to the early95 log phase (4 h p.i.) using SurePrep ${ }^{\mathrm{TM}}$ TrueTotal $^{\mathrm{TM}}$ RNA Purification Kit (Fisher BioReagents) or Total 96 RNA Purification Plus Micro Kit (Norgen). cDNA was generated by iScript gDNA Clear cDNA Synthesis

\section{Microbiota analysis}

Composition of the microbiota was analyzed as described previously (Barman et al., 2008). Groups of CBA mice were mock-infected or infected with the $S$. Typhimurium wild-type (IR715), and samples were collected ten days after infection. The bacterial genomic DNA was extracted using the PowerSoil DNA Isolation Kit (Mo-Bio) according to the manufacturer's instructions. Bacterial DNA was diluted 1:10 and a $0.04 \mathrm{~mL}$ served as the template for SYBR-green based real-time PCR using the primers listed in Table S3. Gene copy number for each sample was determined using standard curves generated from fragments of bacterial 16S rRNA genes (Eubacteria: $R$. productus [ATCC 27340D], Clostridiales: $R$. productus [ATCC 27340D], Lactobacillales/Bacillales: L. acidophilus [ATCC 4357D], Bacteroidetes/Actinobacteria: B. fragilis [ATCC 25285D], Enterobacteriaceae: E. coli [ATCC TOP10]) cloned into pCR2.1 (TOPO TA cloning kit, Invitrogen) as templates. The fraction of each population 
13 was calculated by dividing the gene copy number of each population by the total gene copy number

14 determined using the universal primers.

16 Growth of defined-microbiota (DM) strains

17 Porcine mucin was dissolved in $1 \times$ NCE salts at a final concentration of $0.5 \%(w / v)$. Mucin broth was

18 inoculated with a fresh colony of Bacteroides caecimuris and incubated under anaerobic conditions for

$1972 \mathrm{~h}$ at $37^{\circ} \mathrm{C}$. MRS broth was inoculated with a fresh colony of Lactobacillus reuteri and incubated

20 under anaerobic conditions for $72 \mathrm{~h}$ at $37^{\circ} \mathrm{C}$. BHI broth was inoculated with a fresh colony of Clostridium

21 clostridioforme, Clostridium clostridioforme, Clostridioides mangenotti, Clostridium cochlearium or

22 Clostridium sporogenes strain and incubated under anaerobic conditions for $72 \mathrm{~h}$ at $37^{\circ} \mathrm{C}$.

24 Animal experiments

Animal models of $S$. Typhimurium-induced colitis

CBA mouse model: CBA mice were infected with either $0.1 \mathrm{~mL}$ of LB broth (mock-infected) or

S. Typhimurium IR715 strains in LB broth. Groups $(n=4-5)$ of 6-7 weeks old CBA mice were

29 intragastrically infected with $1 \times 10^{9} \mathrm{CFU}$ for single strain and competitive infection experiments. Fecal

30 samples were collected at days 1, 3 and 7 after infection for bacterial plating. Ten days after infection,

31 samples for histopathology, colonic luminal content and cecal content for $S$. Tm enumeration and

32 aspartate measurements were collected. $S$. Tm numbers were determined by plating serial ten-fold

33 dilutions onto LB agar containing the appropriate antibiotics. For the aspartate-free diet experiments,

34 Groups $(n=5)$ of 6-7 weeks old CBA mice were fed control diet A20073101 (Research Diets) or

35 aspartate-free diet A20073102 (Research Diets) beginning 48h before S. Tm infection and were kept

36 on the diets throughout the experiment. Remaining experiment procedures were performed as 37 described above. 
Germ-Free Swiss Webster (SW) mice: Groups $(n=5)$ of 6-7 weeks old SW germ-free mice were

intragastrically inoculated with $3 \times 10^{9} \mathrm{CFU}$ of Bacteroides caecimuris, Lactobacillus reuteri, or a

combination of Clostridium clostridioforme, Clostridium innocuum, Clostridioides mangenotti,

\section{Animal models of DSS-induced colitis}

Conventional Mice. Male and female 6-7 weeks old wild-type C57BL/6 mice were infected with $1 \times 10^{9} \mathrm{CFU}$ of a $1: 1$ mixture of $E$. coli SP15 strains. One day post infection, mice were given $2.5 \%$ dextran sulfate sodium (DSS; Alfa Aesar) in their drinking water continuously for 7 days. At 8 days postinfection, samples for histopathology, colonic luminal content and cecal content for E. coli SP15 enumeration and aspartate measurements were collected. E. coli SP15 numbers were determined by plating serial ten-fold dilutions onto LB agar containing the appropriate antibiotics. For the aspartatefree diet experiments, groups $(n=5)$ of 6-7 weeks old C57BI/6 mice were fed control diet A20073101 (Research Diets) or aspartate-free diet A20073102 (Research Diets) beginning 48h before E. coli SP15 infection and were kept on the diets throughout the experiment. Remaining experiment procedures were performed as described above.

Germ-Free Swiss Webster (SW) mice: Groups $(\mathrm{n}=5)$ of 6-7 weeks old germ-free SW mice were intragastrically inoculated with $3 \times 10^{9} \mathrm{CFU}$ of Bacteroides caecimuris, Lactobacillus reuteri, or a combination of Clostridium clostridioforme, Clostridium innocuum, Clostridioides mangenotti, Clostridium cochlearium and/or Clostridium sporogenes. A subset of mice were not pre-colonized and 
remained germ-free. After 7 days, pre-colonized and germ-free control animals were infected with with

\section{Caco-2 cell culture}

The human epithelial colorectal adenocarcinoma cell line Caco-2 was obtained from the American Type Culture Collection. Caco-2 cells were routinely maintained in 1x Minimal Essential Media (Gibco), with 10\% Fetal Bovine Serum (Gibco), 1x GlutaMax (Gibco), 1x MEM Nonessential Amino Acids (Corning), $1 \mathrm{mM}$ Sodium Pyruvate (Gibco) at $37^{\circ} \mathrm{C}$ and $5 \% \mathrm{CO}_{2}$.

\section{Invasion assay}

Caco- 2 cells were seeded $2.5 \times 10^{5}$ cells/well and infected with indicated strains at a multiplicity of infection (MOI) of 10 . The bacteria and cells were exposed to hypoxic conditions in a humidified hypoxia chamber $\left(0.8 \% \mathrm{O}_{2}\right)$ while being incubated for $1 \mathrm{~h}$ at $37^{\circ} \mathrm{C}$ in $1 \mathrm{x}$ Minimal Essential Media (Gibco), with 10\% Fetal Bovine Serum (Gibco), 1x GlutaMax (Gibco), 1x MEM Nonessential Amino Acids (Corning), $1 \mathrm{mM}$ Sodium Pyruvate (Gibco). Each well was washed three times with sterile PBS $\left(\mathrm{KCl}\right.$ at $2.7 \mathrm{mM}, \mathrm{KH}_{2} \mathrm{PO}_{4}$ at $1.8 \mathrm{mM}, \mathrm{NaCl}$ at $140 \mathrm{mM}, \mathrm{Na}_{2} \mathrm{HPO}_{4}$ at $\left.10 \mathrm{mM}, \mathrm{pH} 7.4\right)$ to remove extracellular bacteria, and medium containing gentamicin at a concentration of $0.1 \mathrm{mg} / \mathrm{mL}$ was added for a 90 min incubation in conditions stated above. After three washes with PBS, the cells were lysed with $1 \mathrm{~mL}$ of $1 \%$ Triton $\mathrm{X}-100$ and the lysates were transferred to sterile tubes. Tenfold serial dilutions were plated to enumerate intracellular bacteria. 
KEY RESOURCES TABLE

\begin{tabular}{|c|c|c|}
\hline REAGENT or RESOURCE & SOURCE & IDENTIFIER \\
\hline \multicolumn{3}{|l|}{ Bacterial and virus strains } \\
\hline S. Typhimurium, IR715 ATCC $14028 \mathrm{Nal}^{\mathrm{R}}$ & $\begin{array}{l}\text { Stojiljkovic et al., } \\
1995\end{array}$ & IR715 \\
\hline $\begin{array}{l}\text { S. Typhimurium, IR715 } \Delta p h o N:: T n 10 d- \\
\mathrm{Cm}^{R}\end{array}$ & Faber et al., 2016 & FF176 \\
\hline S. Typhimurium, IR715 $\Delta p h o N:: \mathrm{Km}^{\mathrm{R}}$ & Kingsley et al., 2003 & AJB715 \\
\hline S. Typhimurium, IR715 $\Delta \operatorname{tar} \Delta p h o N:: \mathrm{Km}^{\mathrm{R}}$ & This study & WJ65 \\
\hline $\begin{array}{l}\text { S. Typhimurium, IR715 } \Delta \text { aspA } \\
\Delta \text { phoN::Km R }\end{array}$ & This study & WJ66 \\
\hline
\end{tabular}




\begin{tabular}{|c|c|c|}
\hline $\begin{array}{l}\text { S. Typhimurium, IR715 } \Delta d c u A \\
\Delta p h o N:: \mathrm{Km}^{\mathrm{R}}\end{array}$ & This study & WJ57 \\
\hline $\begin{array}{l}\text { S. Typhimurium, IR715 } \triangle \text { frdABCD } \\
\Delta p h o N:: \mathrm{Km}^{\mathrm{R}}\end{array}$ & This study & WJ29 \\
\hline S. Typhimurium, IR715 $\triangle$ frdABCD & This study & WJ28 \\
\hline $\begin{array}{l}\text { S. Typhimurium, IR715 } \triangle \text { frdABCD } \\
\Delta p h o N:: \operatorname{Tn} 10 d-\mathrm{Cm}^{\mathrm{R}}\end{array}$ & This study & WJ30 \\
\hline $\begin{array}{l}\text { S. Typhimurium, IR715 } \triangle \text { frdABCD } \triangle t a r \\
\Delta p h o N:: \mathrm{Km}^{\mathrm{R}}\end{array}$ & This study & WJ67 \\
\hline $\begin{array}{l}\text { S. Typhimurium, IR715 } \triangle \text { frdABCD } \triangle a s p A \\
\Delta p h o N:: \mathrm{Km}^{\mathrm{R}}\end{array}$ & This study & WJ68 \\
\hline $\begin{array}{l}\text { S. Typhimurium, IR715 } \triangle \text { frdABCD } \triangle d c u A \\
\Delta p h o N:: \mathrm{Km}^{\mathrm{R}}\end{array}$ & This study & WJ58 \\
\hline S. Typhimurium, IR715 $\Delta i n v A \Delta s p i B$ & $\begin{array}{l}\text { Rivera-Chávez et al., } \\
2013\end{array}$ & SPN487 \\
\hline $\begin{array}{l}\text { S. Typhimurium, IR715 } \Delta \text { invA } \Delta s p i B \\
\Delta p h o N:: T n 10 d-\mathrm{Cm}^{\mathrm{R}}\end{array}$ & This study & WJ52 \\
\hline 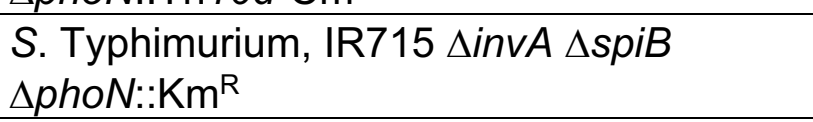 & This study & WJ111 \\
\hline $\begin{array}{l}\text { S. Typhimurium, IR715 } \Delta \text { invA } \Delta \text { spiB } \Delta \text { tar } \\
\Delta \text { phoN::Km }\end{array}$ & This study & WJ125 \\
\hline $\begin{array}{l}\text { S. Typhimurium, IR715 } \Delta \text { invA } \Delta s p i B \Delta a s p A \\
\Delta p h o N:: \mathrm{Km}^{\mathrm{R}}\end{array}$ & This study & WJ133 \\
\hline $\begin{array}{l}\text { S. Typhimurium, IR715 } \Delta \text { invA } \Delta s p i B \Delta d c u A \\
\Delta p h o N:: \mathrm{Km}^{\mathrm{R}}\end{array}$ & This study & WJ135 \\
\hline $\begin{array}{l}\text { S. Typhimurium, IR715 } \Delta i n v A \Delta s p i B \\
\Delta \text { frdABCD } \Delta p h o N:: \mathrm{Km}^{\mathrm{R}}\end{array}$ & This study & WJ143 \\
\hline 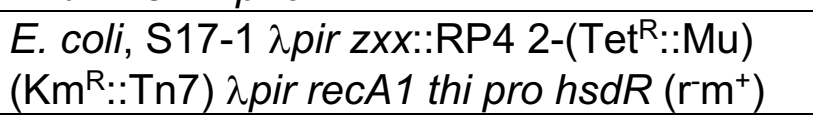 & Simon et al., 1983 & S17-1 $\lambda$ pir \\
\hline 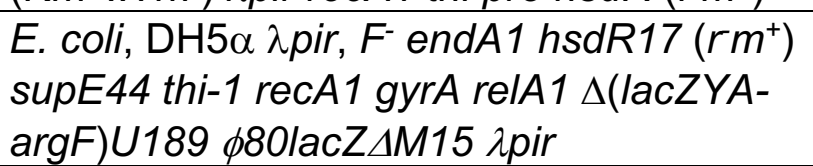 & Grant et al., 1990 & DH5 $\alpha \lambda$ pir \\
\hline E. coli, SP15 & Johnson et al., 2002 & E. coli SP15 \\
\hline E. coli, SP15 $\triangle a s p A:: \mathrm{Km}^{\mathrm{R}}$ & This study & JZ1 \\
\hline E. coli, SP15 $\triangle$ frdABCD:: $\mathrm{Km}^{\mathrm{R}}$ & This study & JZ2 \\
\hline Bacteroides caecimuris & DSMZ & DSMZ 26085 \\
\hline Lactobacillus reuteri & DSMZ & DSMZ 32035 \\
\hline Clostridium clostridioforme & DSMZ & DSMZ 26114 \\
\hline Clostridium innocuum & DSMZ & DSMZ 26113 \\
\hline Clostridioides mangenotti & DSMZ & DSMZ 29133 \\
\hline Clostridium cochlearium & DSMZ & DSMZ 29358 \\
\hline Clostridium sporogenes & DSMZ & DSMZ 29420 \\
\hline \multicolumn{3}{|c|}{ Chemicals, peptides, and recombinant proteins } \\
\hline Gibson Assembly Master Mix & NEB & Cat\# E2611L \\
\hline LB Broth, Miller (Luria Bertani) & Becton Dickinson & Cat\# 244520 \\
\hline LB Agar, Miller (Luria Bertani) & Becton Dickinson & Cat\# 244620 \\
\hline MRS Broth (Difco ${ }^{\mathrm{TM}}$ Lactobacilli) & Becton Dickinson & Cat\# 288130 \\
\hline
\end{tabular}


bioRxiv preprint doi: https://doi.org/10.1101/2022.02.14.480453; this version posted February 15,2022 . The copyright holder for this preprint (which was not certified by peer review) is the author/funder, who has granted bioRxiv a license to display the preprint in perpetuity. It is made available under aCC-BY-NC-ND 4.0 International license.

\begin{tabular}{|c|c|c|}
\hline Bacto Brain Heart Infusion & Becton Dickinson & Cat\# 237500 \\
\hline Sheep Blood & Fisher BioReagents & Cat\# R54008 \\
\hline Bacto Tryptone & Becton Dickinson & Cat\# 211705 \\
\hline L-Aspartic Acid & Fisher Scientific & Cat\# BP374-100 \\
\hline Glycerol & Fisher BioReagents & Cat\# G33-4 \\
\hline Mucin from porcine stomach, Type II & Sigma & Cat\# M2378 \\
\hline Dextran Sulfate Sodium Salt (DSS) & Alfa Aesar & Cat\# J63606 \\
\hline Streptomycin Sulfate & Fisher Scientific & Cat\# BP910-50 \\
\hline TRI Reagent & Molecular Research & Cat\# TR118 \\
\hline iQ SYBR Green Supermix & Bio-Rad & Cat\# 1708882 \\
\hline Platinum PCR Supermix High Fidelity & Invitrogen & Cat\# 12532-016 \\
\hline PCR SuperMix & Invitrogen & Cat\# 10572-014 \\
\hline Acid Casein Peptone & Fisher Scientific & $\begin{array}{l}\text { Cat\# BP1424- } \\
500\end{array}$ \\
\hline Vitamin Supplement & ATCC & Cat\# MD-VS \\
\hline Trace Mineral Supplement & ATCC & Cat\# MD-TMS \\
\hline Minimum Essential Media (MEM) & Gibco & Cat\# 11090081 \\
\hline Fetal Bovine Serum (FBS) & Gibco & Cat\# 10500064 \\
\hline GlutaMAXTM-I & Gibco & Cat\# 35050 \\
\hline $\begin{array}{l}\text { MEM Nonessential Amino Acids Solution } \\
\text { (NEAA) }\end{array}$ & Corning & Cat\# 25-025 \\
\hline Sodium Pyruvate & Gibco & Cat\# 11360070 \\
\hline DPBS & Gibco & Cat\# 14190144 \\
\hline HEPES & Gibco & Cat\# 15630080 \\
\hline Gentamicin Solution & Sigma & Cat\# G1397 \\
\hline \multicolumn{3}{|l|}{ Critical commercial assays } \\
\hline $\begin{array}{l}\text { Aspartate Colorimetric/Fluorometric Assay } \\
\text { Kit }\end{array}$ & BioVision & Cat\# K552 \\
\hline PowerSoil DNA Isolation Kit & Mo-Bio & Cat\# 12888 \\
\hline $\begin{array}{l}\text { SurePrep }{ }^{\mathrm{TM}} \text { TrueTotal }^{\mathrm{TM}} \text { RNA Purification } \\
\text { Kit }\end{array}$ & Fisher BioReagents & Cat\# BP2800 \\
\hline Total RNA Purification Plus Micro Kit & Norgen & Cat\# 48500 \\
\hline iScript gDNA Clear cDNA Synthesis Kit & Bio-Rad & Cat\# 1725035 \\
\hline 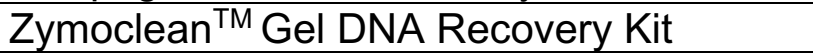 & Zymo Research & Cat\# D4002 \\
\hline PureLink ${ }^{\mathrm{TM}}$ Quick Plasmid Miniprep Kit & Invitrogen & Cat\# K210011 \\
\hline DNeasy PowerSoil Kit & Qiagen & Cat\# 12888 \\
\hline \multicolumn{3}{|c|}{ Experimental models: Organisms/strains } \\
\hline Mouse: C57BL/6J & Jackson Laboratory & Cat\# 000664 \\
\hline Mouse: CBA/J & Jackson Laboratory & Cat\# 000656 \\
\hline Mouse: Germ-free Swiss Webster & Byndloss Lab & N/A \\
\hline Caco-2 & ATCC & Cat\# HTB-37 \\
\hline \multicolumn{3}{|l|}{ Oligonucleotides } \\
\hline Primers used in this study, see Table S1 & This study & N/A \\
\hline \multicolumn{3}{|l|}{ Recombinant DNA } \\
\hline $\begin{array}{l}\text { Plasmid: } \mathrm{pRDH} 10 \text {, ori(R6K) mobRP4 } \\
\text { sacRB } \mathrm{Cm}^{\mathrm{R}} \mathrm{Tet}^{\mathrm{R}}\end{array}$ & Kingsley et al., 1999 & pRDH10 \\
\hline $\begin{array}{l}\text { Plasmid: Up- and downstream region of tar } \\
\text { (IR715) in pRDH10 }\end{array}$ & This study & pWJ39 \\
\hline
\end{tabular}



available under aCC-BY-NC-ND 4.0 International license.

\begin{tabular}{|c|c|c|}
\hline $\begin{array}{l}\text { Plasmid: Up- and downstream region of } \\
\text { aspA (IR715) in pRDH10 }\end{array}$ & This study & pWJ40 \\
\hline $\begin{array}{l}\text { Plasmid: Up- and downstream region of } \\
\text { dcuA (IR715) in pRDH10 }\end{array}$ & This study & pWJ41 \\
\hline $\begin{array}{l}\text { Plasmid: Up- and downstream region of } \\
\text { frdABCD (IR715) in } \mathrm{pRDH} 10\end{array}$ & This study & pWJ51 \\
\hline $\begin{array}{l}\text { Plasmid: pKD46, Spec } \text { P }_{\text {BAD-gam-beta- }} \\
\text { exo oriR101 repA101ts }\end{array}$ & $\begin{array}{l}\text { Datsenko and } \\
\text { Wanner, } 2000\end{array}$ & pKD46 \\
\hline $\begin{array}{l}\text { Plasmid: pKD3, } \text { Carb }^{R} \text { FRT Cm }{ }^{R} \text { FRT PS1 } \\
\text { PS2 oriR } 6 K \gamma\end{array}$ & $\begin{array}{l}\text { Datsenko and } \\
\text { Wanner, } 2000\end{array}$ & pKD3 \\
\hline $\begin{array}{l}\text { Plasmid: pKD13, Carb }{ }^{R} \text { FRT Km }{ }^{R} \text { FRT } \\
\text { PS1 PS4 oriR6K } \gamma\end{array}$ & $\begin{array}{l}\text { Datsenko and } \\
\text { Wanner, } 2000\end{array}$ & pKD13 \\
\hline \multicolumn{3}{|l|}{ Software and algorithms } \\
\hline GraphPad Prism 8 & GrapPad Software & N/A \\
\hline
\end{tabular}

\section{REFERENCES}

Ali, M.M., Newsom, D.L., González, J.F., Sabag-Daigle, A., Stahl, C., Steidley, B., Dubena, J., Dyszel, J.L., Smith, J.N., Dieye, Y., Arsenescu, R., Boyaka, P.N., Krakowka, S., Romeo, T., Behrman, E.J., White, P., and Ahmer, B.M.M. (2014). Fructose-asparagine is a primary nutrient during growth of Salmonella in the inflamed intestine. PLoS Pathog. 10(6), e1004209. DOI: 10.1371/journal.ppat.1004209.

Akram, M. (2014). Citric acid cycle and role of its intermediates in metabolism. Cell Biochem Biophys. 68(3), 475-478. DOI: 10.1007/s12013-013-9750-1.

Arguello, Y.M.S., De Paiva, J.B., Penha Filho, R.A.C., and Berchieri Junior, Â. (2010). Participation of genes involved in the process of anaerobic respiration of infection in chickens by Salmonella Typhimurium. Braz. J. Vet. Pathol. 3(1), 2-8.

Arthur, J.C., and Jobin, C. (2013). The complex interplay between inflammation, the microbiota and colorectal cancer. Gut Microbe. 4(3), 253-258. DOI: 10.4161/gmic.24220.

Arthur, J.C., Gharaibeh, R.Z., Mühlbauer, M., Perez-Chanona, E., Uronis, J.M., McCafferty, J., Fodor, A.A., and Jobin, C. (2014). Microbial genomic analysis reveals the essential role of inflammation in bacteria-induced colorectal cancer. Nat Commun. 5, 4724. DOI: 10.1038/ncomms5724.

Barman, M., Unold, D., Shifley, K., Amir, E., Hung, K., Bos, N., and Salzman, N. (2008). Enteric salmonellosis disrupts the microbial ecology of the murine gastrointestinal tract. Infect Immun. 76(3), 907-915. DOI: 10.1128/IAI.01432-07.

Bronner, D.N., Faber, F., Olsan, E.E., Byndloss, M.X., Sayed, N.A., Xu, G., Yoo, W., Kim, D., Ryu, S., Lebrilla, C.B., and Bäumler, A.J. (2018). Genetic ablation of butyrate utilization attenuates gastrointestinal Salmonella disease. Cell Host Microbe. 23(2), 266-273. DOI: 10.1016/j.chom.2018.01.004

Brugiroux, S., Beutler, M., Pfann, C., Garzetti, D., Ruscheweyh, H.J., Ring, D., Diehl, M., Herp, S., Lötscher, Y., Hussain, S., et al. (2016). Genome-guided design of a defined mouse microbiota that 
confers colonization resistance against Salmonella enterica serovar Typhimurium. Nat Microbiol. 2(2), 16215. DOI: 10.1038/nmicrobiol.2016.215.

Caballero-Flores, G., Pickard, J.M., Fukuda, S., Inohara, N., and Núñez, G. (2020). An enteric pathogen subverts colonization resistance by evading competition for amino acids in the gut. Cell Host Microbe. 28(4), 526-533.e525. DOI: 10.1016/j.chom.2020.06.018.

Coombes, B.K., Coburn, B.A., Potter, A.A., Gomis, S., Mirakhur, K., Li, Y., and Finlay, B.B. (2005). Analysis of the contribution of Salmonella pathogenicity islands 1 and 2 to enteric disease progression using a novel bovine ileal loop model and a murine model of infectious enterocolitis. Infect Immun. 73(11), 7161-7169. DOI: 10.1128/iai.73.11.7161-7169.2005.

de Vos, W.M., Tilg, H., Van Hul, M., and Cani, P.D. (2022). Gut microbiome and health: mechanistic insights. Gut. 0: 1-13. DOI: 10.1136/gutjnl-2021-326789.

Eberl, C., Weiss, A.S., Jochum, L.M., Durai Raj, A.C., Ring, D., Hussain, S., Herp, S., Meng, C., Kleigrewe, K., Gigl, M., et al. (2021). E. coli enhance colonization resistance against Salmonella Typhimurium by competing for galactitol, a context-dependent limiting carbon source. Cell Host Microbe. 29(11), 1680-1692.e1687. DOI: 10.1016/j.chom.2021.09.004.

Faber, F., Thiennimitr, P., Spiga, L., Byndloss, M.X., Litvak, Y., Lawhon, S., Andrews-Polymenis, H.L., Winter, S.E., and Baumler, A.J. (2017). Respiration of microbiota-derived 1,2-propanediol drives Salmonella expansion during colitis. PLoS Pathog. 13(1), e1006129. DOI: 10.1371/journal.ppat.1006129.

Falzone, C.J., Karsten, W.E., Conley, J.D., and Viola, R.E. (1988). L-Aspartate from Escherichia coli: substrate specificity and role of divalent metal ions. Biochemistry. 27(26), 9089-9093. DOI: 10.1021/bi00426a004

Galán, J.E., and Curtiss, R., 3rd (1989). Cloning and molecular characterization of genes whose products allow Salmonella typhimurium to penetrate tissue culture cells. Proc Natl Acad Sci U S A. 86(16), 6383-6387. DOI: 10.1073/pnas.86.16.6383.

Gillis, C.C., Hughes, E.R., Spiga, L., Winter, M.G., Zhu, W., Furtado de Carvalho, T., Chanin, R.B., Behrendt, C.L., Hooper, L.V., Santos, R.L., et al. (2018). Dysbiosis-associated change in host metabolism generates lactate to support Salmonella growth. Cell Host Microbe. 23(4), 570. DOI: 10.1016/j.chom.2018.03.013.

Hughes, E.R., Winter, M.G., Duerkop, B.A., Spiga, L., de Carvalho, T.F., Zhu, W., Gillis, C.C., Büttner, L., Smoot, M.P., Behrendt, C.L., Cherry, S., Santos, R.L., Hooper, L.V., and Winter, S.E. (2017). Microbial respiration and formate oxidation as metabolic signature of inflammation-associated dysbiosis. Cell Host Microbe. 21(2), 208-219. DOI: 10.1016/j.chom.2017.01.005.

Iverson, T.M., Luna-Chavez, C., Cecchini, G., and Rees, D.C. (1999). Structure of the Escherichia coli fumarate reductase respiratory complex. Science. 284(5422), 1961-1966. DOI:

10.1126/science.284.5422.1961.

Johnson, J.R., Oswald, E., O'Bryan, T.T., Kuskowski, M.A., and Spanjaard, L. (2002). Phylogenetic distribution of virulence-associated genes among Escherichia coli isolates associated with neonatal bacterial meningitis in the Netherlands. J Infect Dis. 185(6), 774-784. DOI: 10.1086/339343. 
Jones, S.A., Chowdhury, F.Z., Fabich, A.J., Anderson, A., Schreiner, D.M., House, A.L., Autieri, S.M., Leatham, M.P., Lins, J.J., Jorgensen, M., et al. (2007). Respiration of Escherichia coli in the mouse intestine. Infect Immun. 75(10), 4891-4899. DOI: 10.1128/iai.00484-07.

Kitamoto, S., Alteri, C.J., Rodrigues, M., Nagao-Kitamoto, H., Sugihara, K., Himpsl, S.D., Bazzi, M., Miyoshi, M., Nishioka, T., Hayashi, A., et al. (2020). Dietary l-serine confers a competitive fitness advantage to Enterobacteriaceae in the inflamed gut. Nature Microbiology. 5(1), 116-125. DOI: 10.1038/s41564-019-0591-6.

Krautkramer, K.A., Fan, J., and Bäckhed, F. (2021). Gut microbial metabolites as multi-kingdom intermediates. Nat Rev Microbiol. 19(2), 77-94. DOI: 10.1038/s41579-020-0438-4.

Li, H., Zhou, X., Huang, Y., Liao, B., Cheng, L., and Ren, B. (2020). Reactive oxygen species in pathogen clearance: The killing mechanisms, the adaption response, and the side effects. Front Microbiol. 11, 622534. DOI: 10.3389/fmicb.2020.622534.

Lin, L., and Zhang, J. (2017). Role of intestinal microbiota and metabolites on gut homeostasis and human diseases. BMC Immunol. 18(1), 2. DOI: 10.1186/s12865-016-0187-3.

Litvak, Y., Mon, K.K.Z., Nguyen, H., Chanthavixay, G., Liou, M., Velazquez, E.M., Kutter, L., Alcantara, M.A., Byndloss, M.X., Tiffany, C.R., et al. (2019). Commensal Enterobacteriaceae protect against Salmonella colonization through oxygen competition. Cell Host Microbe. 25(1), 128-139.e125. DOI: 10.1016/j.chom.2018.12.003.

Lopez, C.A., Rivera-Chávez, F., Byndloss, M.X., and Bäumler, A.J. (2015). The periplasmic nitrate reductase NapABC supports luminal growth of Salmonella enterica serovar Typhimurium during colitis. Infect. Immun. 83, 3470-3478. DOI: 10.1128/IAI.00351-15.

Lopez, C.A., Winter, S.E., Rivera-Chávez, F., Xavier, M.N., Poon, V., Nuccio, S.P., Tsolis, R.M., and Bäumler, A.J. (2012). Phage-mediated acquisition of a type III secreted effector protein boosts growth of Salmonella by nitrate respiration. MBio 3(3), e00143-12. DOI: 10.1128/mBio.00143-12

Mercado-Lubo, R., Gauger, E.J., Leatham, M.P., Conway, T., and Cohen, P.S. (2008). A Salmonella enterica serovar typhimurium succinate dehydrogenase/fumarate reductase double mutant is avirulent and immunogenic in BALB/c mice. Infect Immun. 76(3), 1128-1134. DOI: 10.1128/iai.0122607.

Morris, S.M., Jr. (2002). Regulation of enzymes of the urea cycle and arginine metabolism. Annu Rev Nutr. 22, 87-105. DOI: 10.1146/annurev.nutr.22.110801.140547.

Nguyen, B.D., Cuenca, V.M., Hartl, J., Gül, E., Bauer, R., Meile, S., Rüthi, J., Margot, C., Heeb, L., Besser, F., et al. (2020). Import of aspartate and malate by DcuABC drives $\mathrm{H}_{2} /$ Fumarate respiration to promote initial Salmonella gut-lumen colonization in mice. Cell Host Microbe. 27(6), 922-936.e926. DOI: 10.1016/j.chom.2020.04.013.

Nógrády, N., Imre, A., Rychlik, I., Barrow, P.A., and Nagy, B. (2003). Genes responsible for anaerobic fumarate and arginine metabolism are involved in growth suppression in Salmonella enterica serovar Typhimurium in vitro, without influencing colonisation inhibition in the chicken in vivo. Vet Microbiol. 97(3-4), 191-199. DOI: 10.1016/j.vetmic.2003.08.011. 
Oliphant, K., and Allen-Vercoe, E. (2019). Macronutrient metabolism by the human gut microbiome: major fermentation by-products and their impact on host health. Microbiome. 7(1), 91. DOI: 10.1186/s40168-019-0704-8.

Paiva, J.B., Penha Filho, R.A., Pereira, E.A., Lemos, M.V., Barrow, P.A., Lovell, M.A., and Berchieri, A., Jr. (2009). The contribution of genes required for anaerobic respiration to the virulence of Salmonella enterica serovar Gallinarum for chickens. Braz J Microbiol. 40(4), 994-1001. DOI: 10.1590/s1517-838220090004000035.

Plant, J., and Glynn, A.A. (1976). Genetics of resistance to infection with Salmonella typhimurium in mice. J Infect Dis. 133(1), 72-78. DOI: 10.1093/infdis/133.1.72.

Popp, J., Noster, J., Busch, K., Kehl, A., Zur Hellen, G., and Hensel, M. (2015). Role of host cellderived amino acids in nutrition of intracellular Salmonella enterica. Infect Immun. 83(12), 4466-4475. DOI: 10.1128/iai.00624-15.

Raffatellu, M., George, M.D., Akiyama, Y., Hornsby, M.J., Nuccio, S.P., Paixao, T.A., Butler, B.P., Chu, H., Santos, R.L., Berger, T., et al. (2009). Lipocalin-2 resistance confers an advantage to Salmonella enterica serotype Typhimurium for growth and survival in the inflamed intestine. Cell Host Microbe. 5(5), 476-486. DOI: 10.1016/j.chom.2009.03.011.

Rivera-Chávez, F., Winter, S.E., Lopez, C.A., Xavier, M.N., Winter, M.G., Nuccio, S.P., Russell, J.M., Laughlin, R.C., Lawhon, S.D., Sterzenbach, T., Bevins, C.L., Tsolis, R.M., Harshey, R., Adams, L.G., and Bäumler, A.J. (2013). Salmonella uses energy taxis to benefit from intestinal inflammation. PLoS Pathog. 9(4), e1003267. DOI: 10.1371/journal.ppat.1003267

Rivera-Chávez, F., Zhang, L.F., Faber, F., Lopez, C.A., Byndloss, M.X., Olsan, E.E., Xu, G., Velazquez, E.M., Lebrilla, C.B., Winter, S.E., et al. (2016). Depletion of butyrate-producing Clostridia from the gut microbiota drives an aerobic luminal expansion of Salmonella. Cell Host Microbe. 19(4), 443-454. DOI: 10.1016/j.chom.2016.03.004.

Salway, J.G. (2018). The Krebs Uric Acid Cycle: A Forgotten Krebs Cycle. Trends Biochem Sci. 43(11), 847-849. DOI: 10.1016/j.tibs.2018.04.012.

Schrimpe-Rutledge, A.C., Codreanu, S.G., Sherrod, S.D., and McLean, J.A. (2016). Untargeted metabolomics strategies-challenges and emerging directions. J Am Soc Mass Spectrom. 27(12), 1897-1905. DOI: 10.1007/s13361-016-1469-y.

Schubert, C., Winter, M., Ebert-Jung, A., Kierszniowska, S., Nagel-Wolfrum, K., Schramm, T., Link, H., Winter, S., and Unden, G. (2021). C4-dicarboxylates and I-aspartate utilization by Escherichia coli $\mathrm{K}-12$ in the mouse intestine: I-aspartate as a major substrate for fumarate respiration and as a nitrogen source. Environ Microbiol. 23(5), 2564-2577. DOI: 10.1111/1462-2920.15478.

Shealy, N.G., Yoo, W., and Byndloss, M.X. (2021). Colonization resistance: metabolic warfare as a strategy against pathogenic Enterobacteriaceae. Curr Opin Microbiol. 64, 82-90. DOI: 10.1016/j.mib.2021.09.014.

Shelton, C.D., Yoo, W., Shealy, N.G., Torres, T.P., Zieba, J.K., Calcutt, M.W., Foegeding, N.J., Kim, D., Kim, J., Ryu, S., et al. (2022). Salmonella Typhimurium uses anaeorbic respiration to overcome propionate-mediated colonization resistance. Cell Rep. 38(1): 110180. DOI:

10.1016/j.celrep.2021.110180. 
Slocum, M.K., and Parkinson, J.S. (1985). Genetics of methyl-accepting chemotaxis proteins in Escherichia coli: null phenotypes of the tar and tap genes. J Bacteriol. 163(2): 586-594. DOI: 10.1128/jb.163.2.586-594.1985.

Takiishi, T., Fenero, C.I.M., and Câmara, N.O.S. (2017). Intestinal barrier and gut microbiota: Shaping our immune responses throughout life. Tissue Barriers. 5(4), e1373208. DOI: 10.1080/21688370.2017.1373208.

Tang, Z.Z., Chen, G., Hong, Q., Huang, S., Smith, H.M., Shah, R.D., Scholz, M., and Ferguson, J.F. (2019). Multi-mic Analysis of the Microbiome and Metabolome in Healthy Subjects Reveals Microbiome-Dependent Relationships Between Diet and Metabolites. Front Genet. 10, 454. DOI: 10.3389/fgene.2019.00454.

Thiennimitr, P., Winter, S.E., Winter, M.G., Xavier, M.N., Tolstikov, V., Huseby, D.L., Sterzenbach, T., Tsolis, R.M., Roth, J.R., and Bäumler, A.J. (2011). Intestinal inflammation allows Salmonella to use ethanolamine to compete with the microbiota. Proc. Natl. Acad. Sci. USA 108(42), 17480-17485. DOI: 10.1073/pnas. 1107857108

Velazquez, E.M., Nguyen, H., Heasley, K.T., Saechao, C.H., Gil, L.M., Rogers, A.W.L., Miller, B.M., Rolston, M.R., Lopez, C.A., Litvak, Y., et al. (2019). Endogenous Enterobacteriaceae underlie variation in susceptibility to Salmonella infection. Nat Microbiol. 4(6), 1057-1064. DOI: 10.1038/s41564-019-0407-8.

Winter, S.E., Thiennimitr, P., Winter, M.G., Butler, B.P., Huseby, D.L., Crawford, R.W., Russell, J.M., Bevins, C.L., Adams, L.G., Tsolis, R.M., Roth, J.R., and Bäumler, A.J. (2010). Gut inflammation provides a respiratory electron acceptor for Salmonella. Nature. 467(7314), 426-429. DOI: 10.1038/nature09415.

Wotzka, S.Y., Kreuzer, M., Maier, L., Arnoldini, M., Nguyen, B.D., Brachmann, A.O., Berthold, D.L., Zünd, M., Hausmann, A., Bakkeren, E., et al. (2019). Escherichia coli limits Salmonella Typhimurium infections after diet shifts and fat-mediated microbiota perturbation in mice. Nat Microbiol. 4(12), 2164-2174. DOI: 10.1038/s41564-019-0568-5.

Yoo, W., Byndloss, M.X. (2020). How to thrive in the inflamed gut. Nat Microbiol. 5(1), 10-11. DOI: 10.1038/s41564-019-0642-z.

Zhu, W., Miyata, X., Winter, M.G., Arenales, A., Hughes, E.R., Spiga, L., Kim, J., SifuentesDominguez, L., Starokadomskyy, P., Gopal, P., Byndloss, M.X., Santos, R.L., Burstein, E., and Winter, S.E. (2019). Editing of the gut microbiota reduces carcinogenesis in mouse models of colitisassociated colorectal cancer. J Exp Med. 216(10), 2378-2393. DOI: 10.1084/jem.20181939.

Zierer, J., Jackson, M.A., Kastenmüller, G., Mangino, M., Long, T., Telenti, A., Mohney, R.P., Small, K.S., Bell, J.T., Steves, C.J., et al. (2018). The fecal metabolome as a functional readout of the gut microbiome. Nat Genet. 50(6), 790-795. DOI: 10.1038/s41588-018-0135-7. 
bioRxiv preprint doi: https://doi.org/10.1101/2022 02 14.480453; this version posted February 15, 2022. The copyright holder for this preprint (which was not certified by peer review) is the author/funder, who has granted bioRxiv a license to display the preprint in perpetuity. It is made available under aCC-BY-NC-ND 4.0 International license.

FIGURE 1
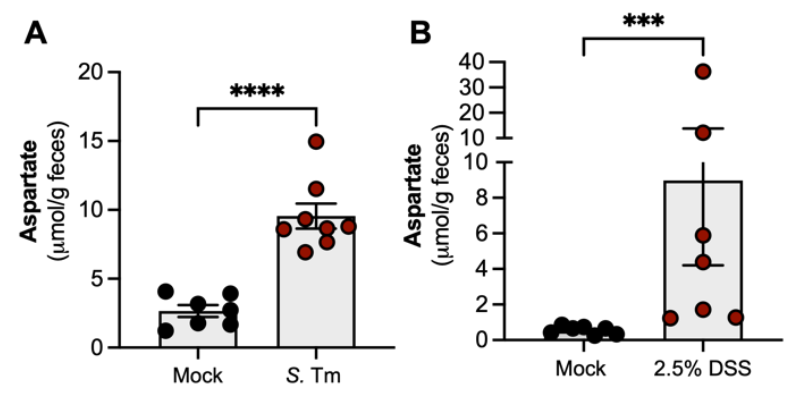

E

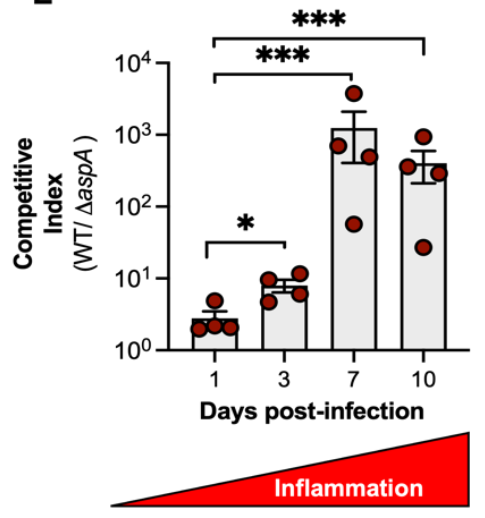

C

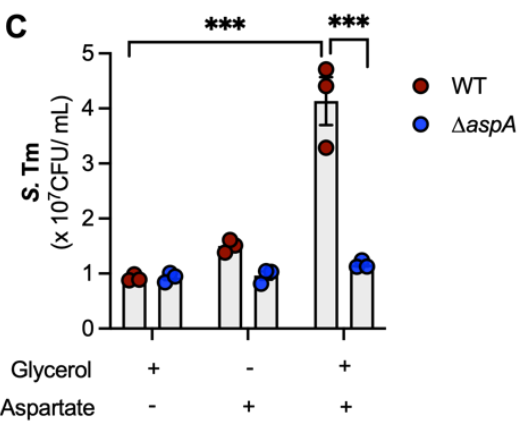

F

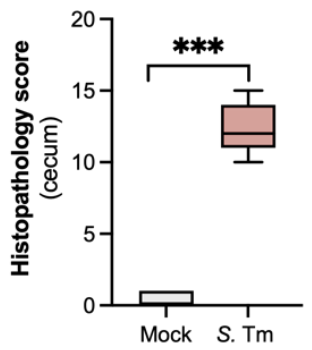

G

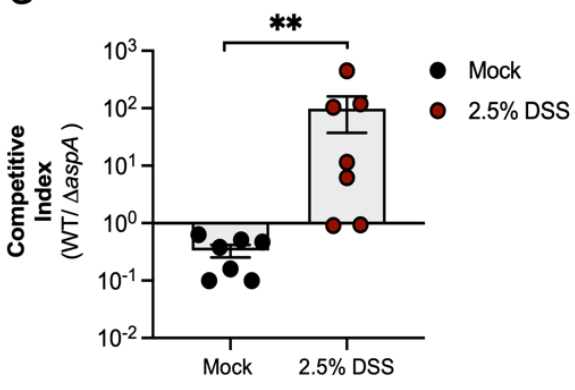

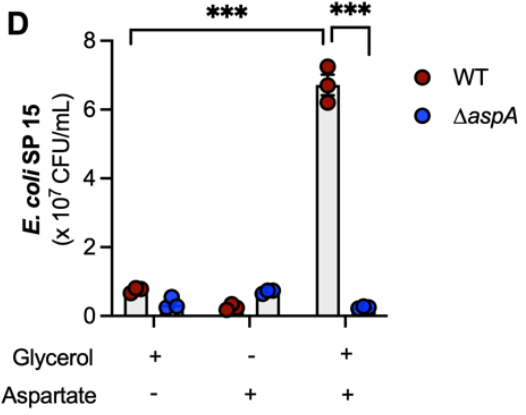

H

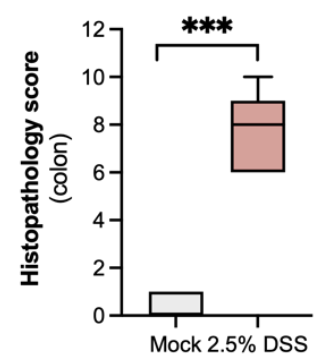


bioRxiv preprint doi: https://doi.org/10.1101/2022.02.14.480453; this version posted February 15,2022 . The copyright holder for this preprint (which was not certified by peer review) is the author/funder, who has granted bioRxiv a license to display the preprint in perpetuity. It is made available under aCC-BY-NC-ND 4.0 International license.

FIGURE 2

A

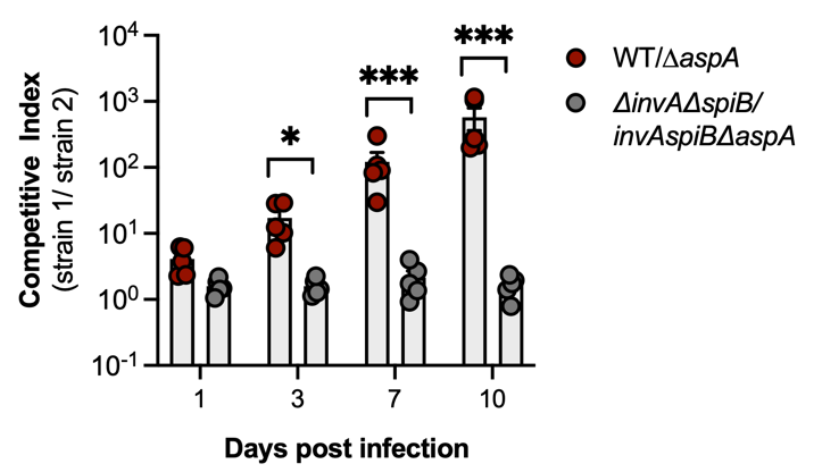

B

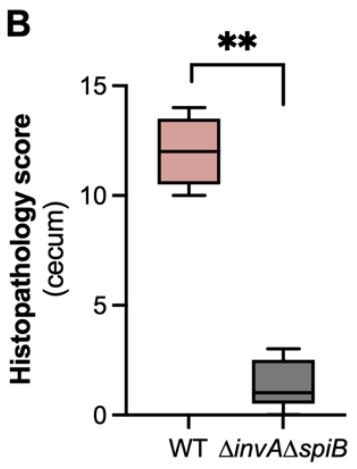

E

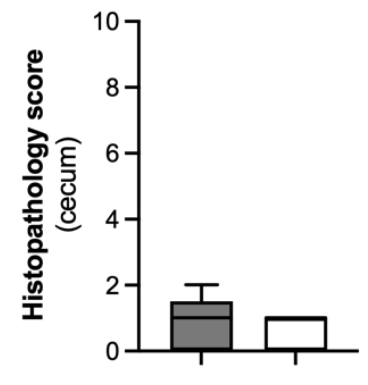

Aspartate
C

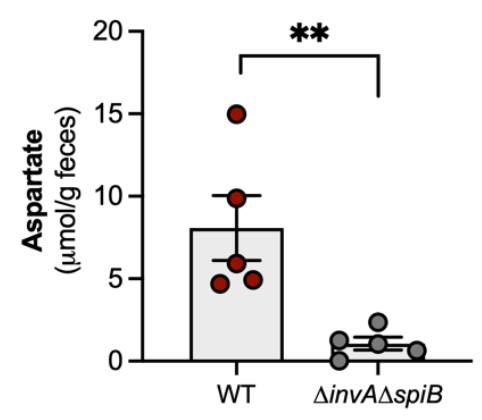

D

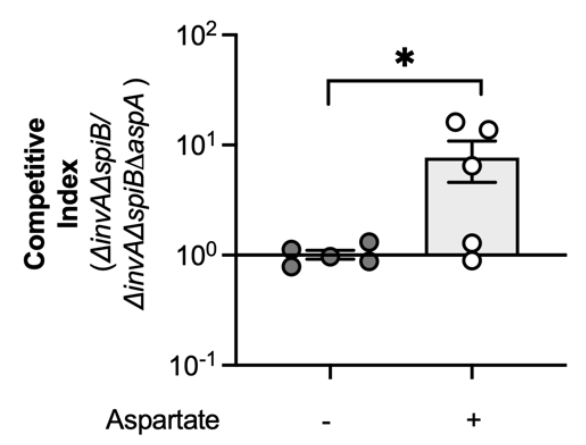

F

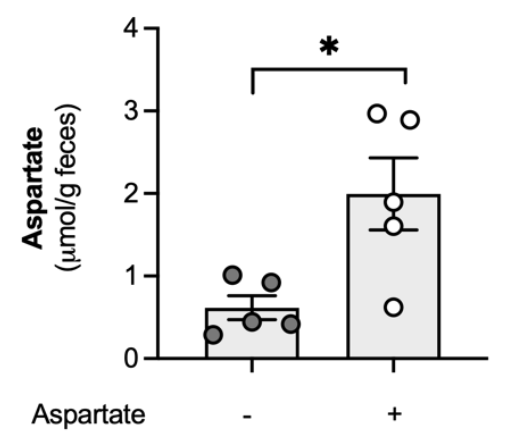


bioRxiv preprint dol: https://doi.org/10.1101/2022.02.14.480453; this version posted February 15,2022 . The copyright holder for this preprint

(which was not certified by peer review) is the author/funder, who has granted bioRxiv a license to display the preprint in perpetuity. It is made available under aCC-BY-NC-ND 4.0 International license.

FIGURE 3

A

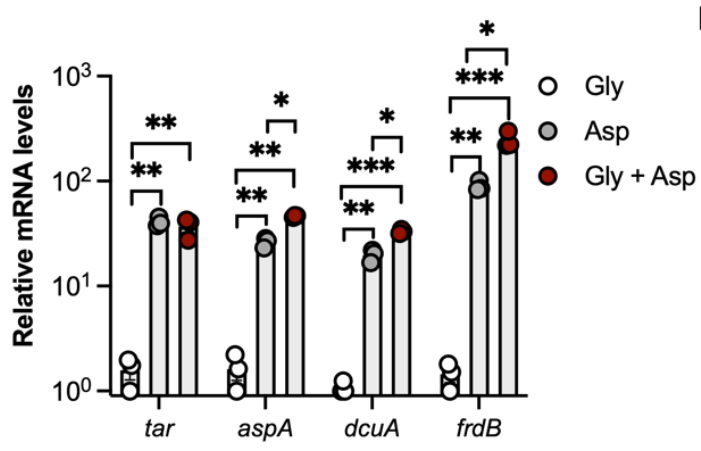

D

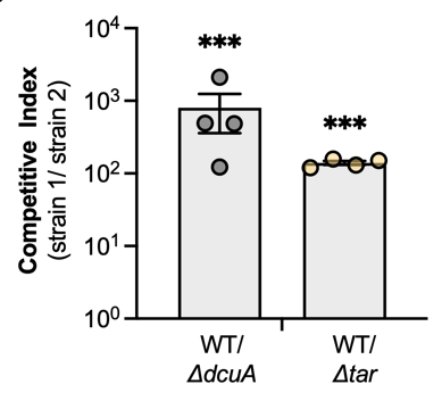

E

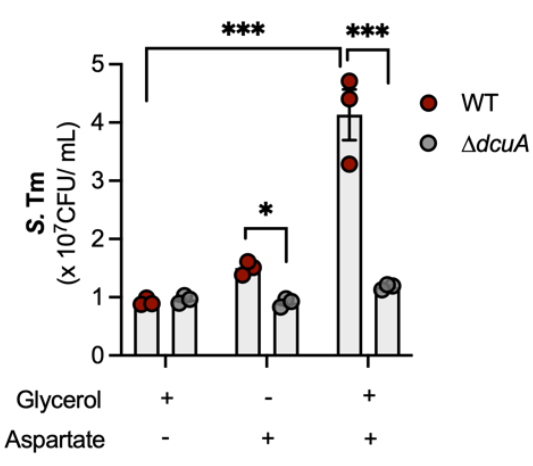

C

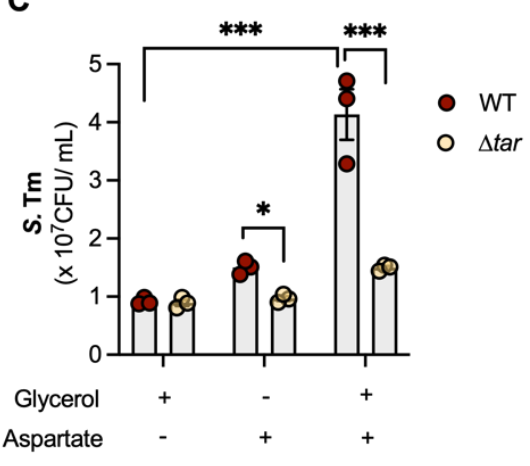

13
14
15
16

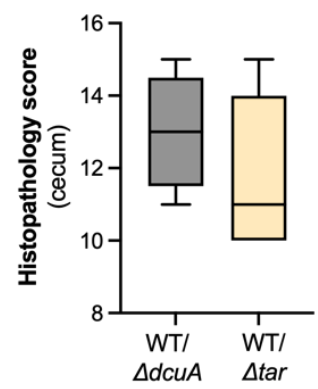

41 
bioRxiv preprint dol: https://doi.org/10.1101/2022.02.14.480453; this version posted February 15, 2022. The copyright holder for this preprint (which was not certified by peer review) is the author/funder, who has granted bioRxiv a license to display the preprint in perpetuity. It is made available under aCC-BY-NC-ND 4.0 International license.

17 FIGURE 4

A
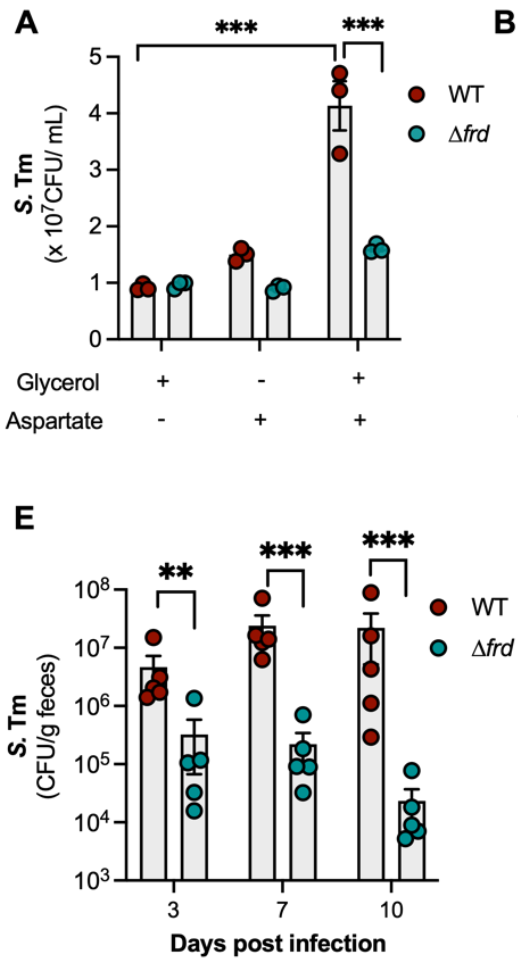

B

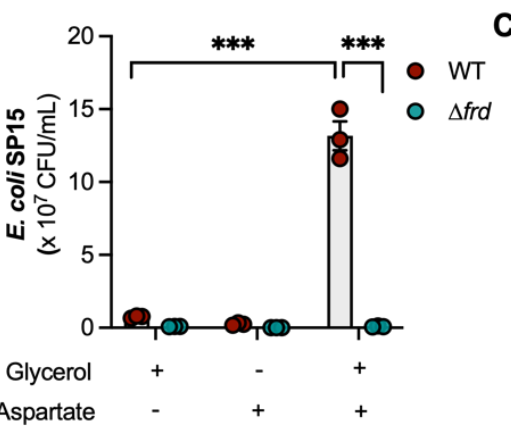

$\mathbf{F}$

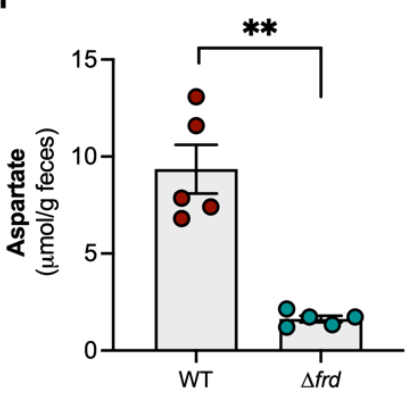

C

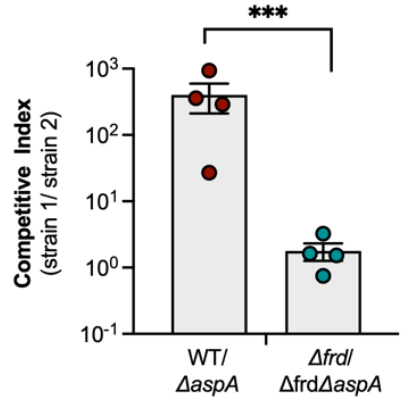

$\mathbf{G}$

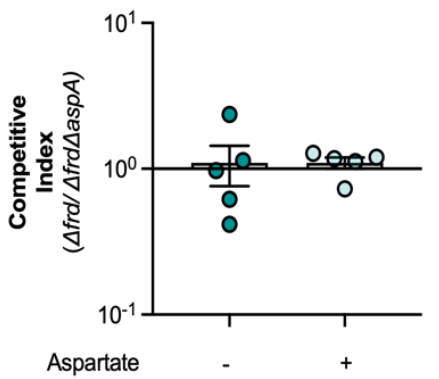

D

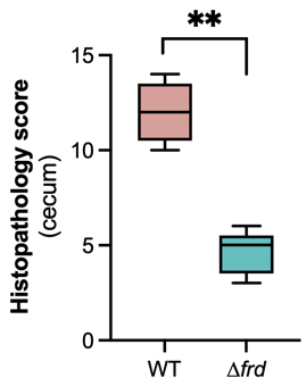

H

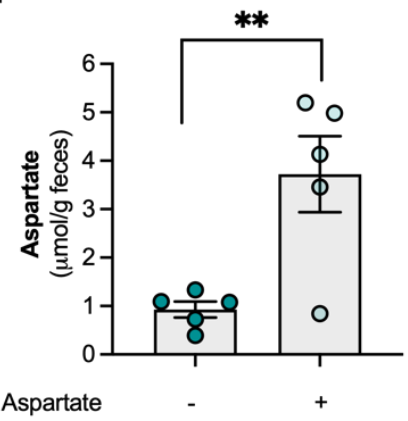

18

19

20

42 


\section{FIGURE 5}

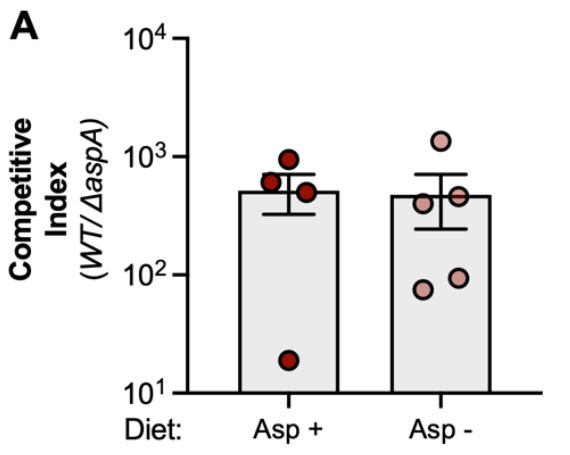

D

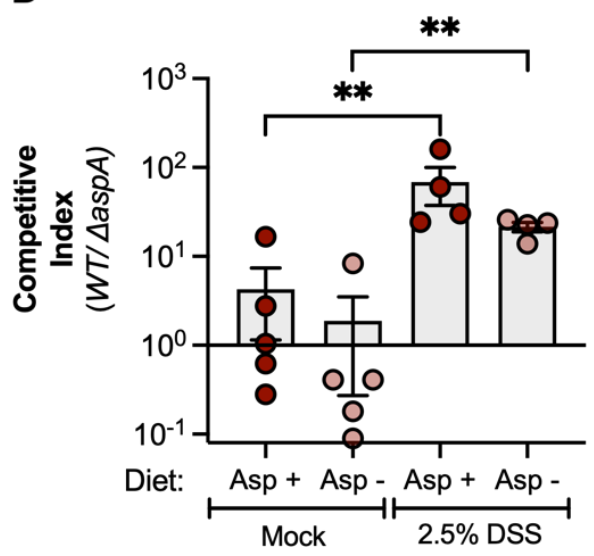

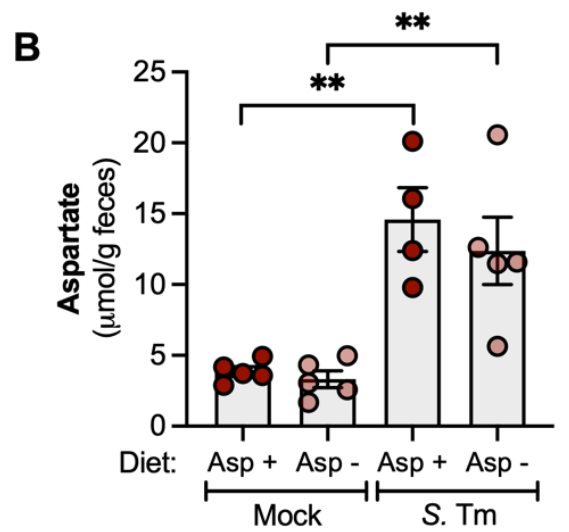

E

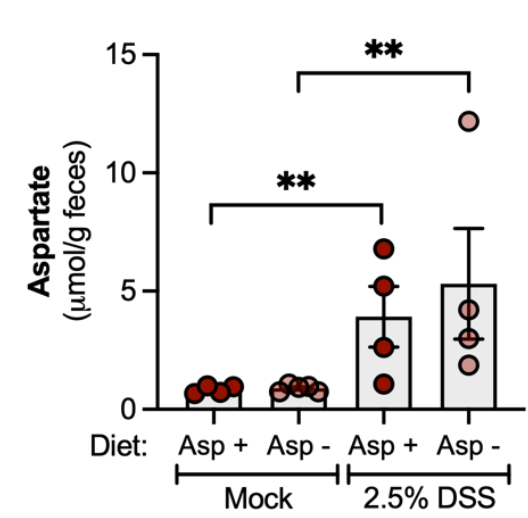

C

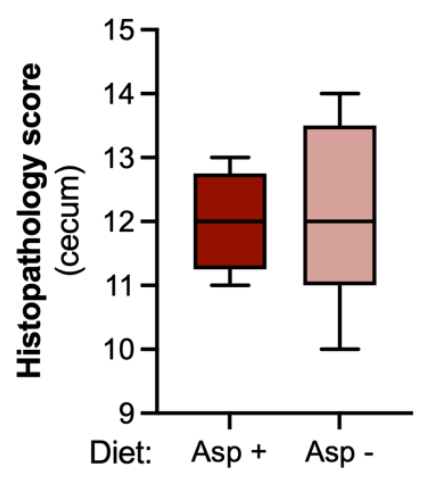

$\mathbf{F}$

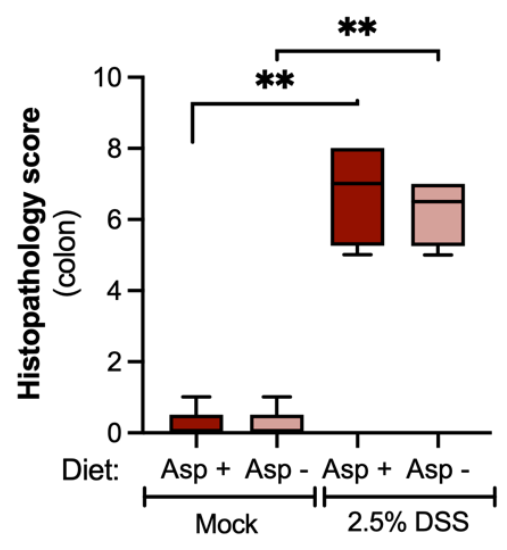




\section{FIGURE 6}

A

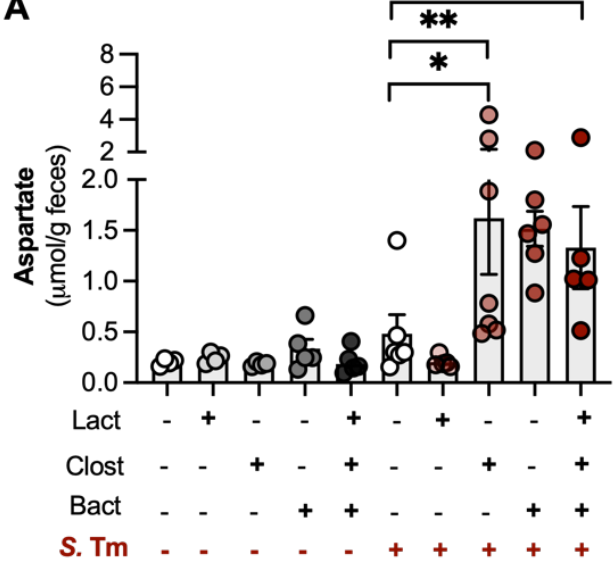

D

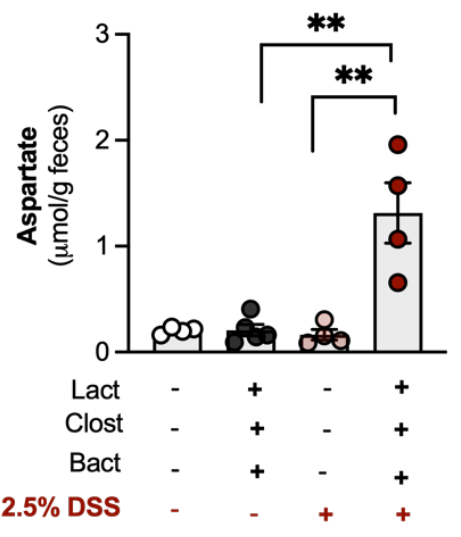

B

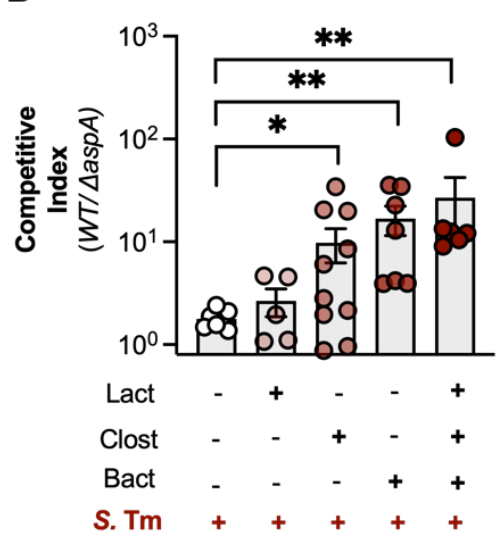

E

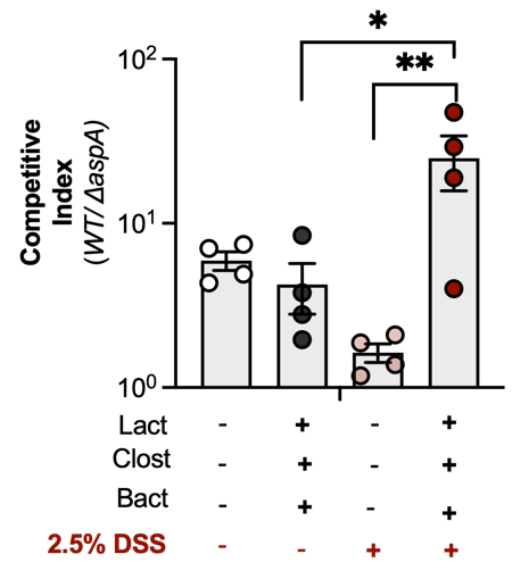

C

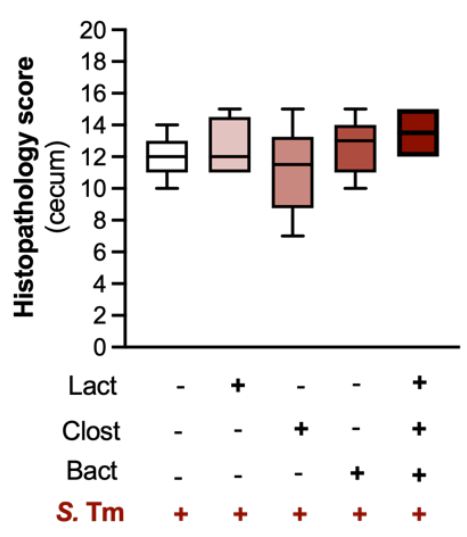

F

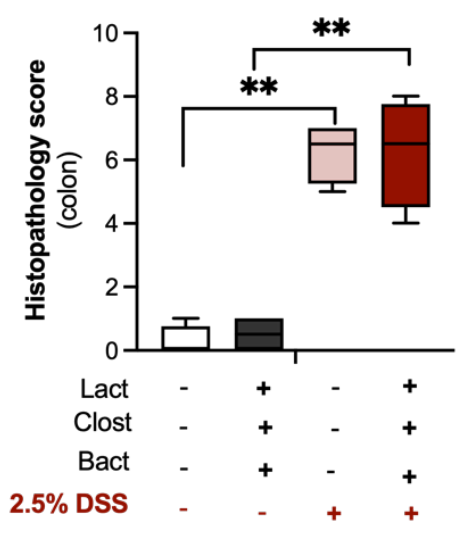


SUPPLEMENTARY MATERIAL

Table S1. Primers used to construct plasmids and bacterial strains.

\begin{tabular}{|c|c|c|}
\hline Name & Sequence $\left(5^{\prime} \rightarrow>3^{\prime}\right)$ & References \\
\hline $\begin{array}{l}\text { IR715-tar-del- } \\
\text { F1 }\end{array}$ & $\begin{array}{l}\text { TCT CAA GGG CAT CGC GTA TCC GCG TTG TCA } \\
\text { CAA T }\end{array}$ & This study \\
\hline $\begin{array}{l}\text { IR715-tar-del- } \\
\text { R1 }\end{array}$ & $\begin{array}{l}\text { TAT TAC CGG CCG GGC GTA ATT GCC CAG } \\
\text { CGC }\end{array}$ & This study \\
\hline $\begin{array}{l}\text { IR715-tar-del- } \\
\text { F2 }\end{array}$ & ATT ACG CCC GGC CGG TAA TAC CGA CCT CTC & This study \\
\hline $\begin{array}{l}\text { IR715-tar-del- } \\
\text { R2 }\end{array}$ & $\begin{array}{l}\text { GCA TAA GGG AGA GCG ACG CGC GTA ACG } \\
\text { GCA TTG AC }\end{array}$ & This study \\
\hline $\begin{array}{l}\text { IR715-aspA-del- } \\
\text { F1 }\end{array}$ & $\begin{array}{l}\text { TCT CAA GGG CAT CGA TCA GCG ACA TCC CTG } \\
\text { АAT T }\end{array}$ & This study \\
\hline $\begin{array}{l}\text { IR715-aspA-del- } \\
\text { R1 }\end{array}$ & $\begin{array}{l}\text { CAG AAG AGA GAA CGC ACG GAA TTC TTG } \\
\text { ACC }\end{array}$ & This study \\
\hline $\begin{array}{l}\text { IR715-aspA-del- } \\
\text { F2 }\end{array}$ & TCC GTG CGT TCT CTC TTC TGG TCC TCG TGC & This study \\
\hline $\begin{array}{l}\text { IR715-aspA-del- } \\
\text { R2 }\end{array}$ & $\begin{array}{l}\text { GCA TAA GGG AGA GCG TAA GCC GGG TGC } \\
\text { ATC AAG TT }\end{array}$ & This study \\
\hline $\begin{array}{l}\text { IR715-dcuA-del- } \\
\text { F1 }\end{array}$ & $\begin{array}{l}\text { TCT CAA GGG CAT CGC GAT GGC GGC GGA } \\
\text { AGC CGG T }\end{array}$ & This study \\
\hline $\begin{array}{l}\text { IR715-dcuA-del- } \\
\text { R1 }\end{array}$ & CAG TCG ATG TAT TAG CCT TCC TTG TTG TTT & This study \\
\hline $\begin{array}{l}\text { IR715-dcuA-del- } \\
\text { F2 }\end{array}$ & GAA GGC TAA TAC ATC GAC TGG ATC AAA GAC & This study \\
\hline
\end{tabular}


bioRxiv preprint doi: https://doi.org/10.1101/2022.02.14.480453; this version posted February 15, 2022. The copyright holder for this preprint (which was not certified by peer review) is the author/funder, who has granted bioRxiv a license to display the preprint in perpetuity. It is made available under aCC-BY-NC-ND 4.0 International license.

\begin{tabular}{|c|c|c|}
\hline $\begin{array}{l}\text { IR715-dcuA-del- } \\
\text { R2 }\end{array}$ & $\begin{array}{l}\text { GCA TAA GGG AGA GCG ACT CTT AAC ATC AAG } \\
\text { CAT AA }\end{array}$ & This study \\
\hline $\begin{array}{l}\text { IR715-frdABCD- } \\
\text { del-F1 }\end{array}$ & $\begin{array}{l}\text { TCT CAA GGG CAT CGA CCG ATT CCA GTA CGT } \\
\text { CCG A }\end{array}$ & This study \\
\hline $\begin{array}{l}\text { IR715-frdABCD- } \\
\text { del-R1 }\end{array}$ & GGG TTC ATC ATC AGA CCA TGA CCC AGT TCG & This study \\
\hline $\begin{array}{l}\text { IR715-frdABCD- } \\
\text { del-F2 }\end{array}$ & CAT GGT CTG ATG ATG AAC CCG TAT TCT GGG & This study \\
\hline $\begin{array}{l}\text { IR715-frdABCD- } \\
\text { del-R2 }\end{array}$ & $\begin{array}{l}\text { GCA TAA GGG AGA GCG AGG CGA CAA CCA } \\
\text { AAA ATG CC }\end{array}$ & This study \\
\hline $\begin{array}{l}\text { SP15-aspA-del- } \\
\text { F1 }\end{array}$ & $\begin{array}{l}\text { TGT TCG CGG TAT GGT AAT GGT TAA AAA AGC } \\
\text { CGC AGC TAT GTG TAG GCT GGA GCT GCT } \\
\text { TCG }\end{array}$ & This study \\
\hline $\begin{array}{l}\text { SP15-aspA-del- } \\
\text { R1 }\end{array}$ & $\begin{array}{l}\text { TTA GCT GGC ATG ATG GAA GAG CCT GCC } \\
\text { TGC AGT TCC GGC AAT ATG AAT ATC CTC CTT } \\
\text { AGT TC }\end{array}$ & This study \\
\hline $\begin{array}{l}\text { SP15-frdABCD- } \\
\text { del-F1 }\end{array}$ & $\begin{array}{l}\text { AGT ACG GGG CTG TGG GAT AAA AAC AAT CTG } \\
\text { GAG GAA TGT CTG TAG GCT GGA GCT GCT } \\
\text { TCG }\end{array}$ & This study \\
\hline $\begin{array}{l}\text { SP15-frdABCD- } \\
\text { del-R1 }\end{array}$ & $\begin{array}{l}\text { CAG AAC GCG CTC GTA GCT CAG TGC ATC } \\
\text { ACC CGG AAA CAG CAT TCC GGG GAT CCG } \\
\text { TCG ACC }\end{array}$ & This study \\
\hline
\end{tabular}


bioRxiv preprint doi: https://doi.org/10.1101/2022.02.14.480453; this version posted February 15,2022 . The copyright holder for this preprint (which was not certified by peer review) is the author/funder, who has granted bioRxiv a license to display the preprint in perpetuity. It is made available under aCC-BY-NC-ND 4.0 International license.

\begin{tabular}{|c|c|c|}
\hline Name & Description & References \\
\hline $\mathrm{pRDH} 10$ & ori(R6K) mobRP4 sacRB $\mathrm{Cm}^{\mathrm{R}} \mathrm{Tet}^{\mathrm{R}}$ & $\begin{array}{c}\text { Kingsley et al., } \\
1999\end{array}$ \\
\hline pKD46 & Spec $^{R} P_{\text {BAD-gam-beta-exo oriR101 repA101ts }}$ & $\begin{array}{l}\text { Datsenko and } \\
\text { Wanner, } 2000\end{array}$ \\
\hline pKD3 & Carb $^{R}$ FRT CmR FRT PS1 PS2 oriR6K $\gamma$ & $\begin{array}{l}\text { Datsenko and } \\
\text { Wanner, } 2000\end{array}$ \\
\hline pKD13 & Carb $^{R}$ FRT Km R FRT PS1 PS4 oriR6K $\gamma$ & $\begin{array}{l}\text { Datsenko and } \\
\text { Wanner, } 2000\end{array}$ \\
\hline pCP20 & Carb $^{R} \mathrm{Cm}^{\mathrm{R}}$ c/857 $\lambda \mathrm{P}_{\mathrm{R}}$ flp oripSC101ts & $\begin{array}{l}\text { Datsenko and } \\
\text { Wanner, } 2000\end{array}$ \\
\hline pWJ39 & pRDH10:: $\Delta t a r$ & This study \\
\hline pWJ40 & pRDH10:: $\triangle a s p A$ & This study \\
\hline pWJ41 & $\mathrm{pRDH} 10:: \Delta d c u A$ & This study \\
\hline pWJ51 & pRDH10:: $\triangle$ frdABCD & This study \\
\hline
\end{tabular}



available under aCC-BY-NC-ND 4.0 International license.

\section{Table S3. qRT-PCR primers for Salmonella gene expression.}

\begin{tabular}{|l|l|c|}
\hline \multicolumn{1}{|c|}{ Name } & \multicolumn{1}{|c|}{ Sequence (5' -> 3') } & References \\
\hline tar-qPCR-F & TGC CCT GCT TAA CCC ATT AG & This study \\
\hline tar-qPCR-R & ACG GGA AGA GAG GTC GGT AT & This study \\
\hline aspA-qPCR-F & CTG TGG CGC ATA TGT TAT GG & This study \\
\hline aspA-qPCR-R & TCG TAA CGG TGG TGT CGT TA & This study \\
\hline dcuA-qPCR-F & AGG AGC AGG GAA TCA AAC CT & This study \\
\hline dcuA-qPCR-R & ACC AGG AAG GAC ATC ACC AG & This study \\
\hline frdB-qPCR-F & TAA CCC GGA AAC CGA TAC C & This study \\
\hline frdB-qPCR-R & CAG CGC TTC CAC CTT CAT A & This study \\
\hline 16S rRNA-qPCR-F & TGT TGT GGT TAA TAA CCG CA & This study \\
\hline 16S rRNA-qPCR-R & GAC TAC CAG GGT ATC TAA TCC & This study \\
\hline Eubacteria 16S rRNA-F & ACT CCT ACG GGA GGC AGC AGT & Barman et \\
\hline 16S rRNA-F & & al., 2008 \\
\hline Clostridiales 16S rRNA-R & GCT TCT TTA GTC AGG TAC CGT CAT & Barman et \\
\hline Eubacteria 16S rRNA-F & ATT ACC GCG GCT GCT GGC & Barman et \\
& & ACT CCT ACG GGA GGC AGC \\
\hline
\end{tabular}


bioRxiv preprint doi: https://doi.org/10.1101/2022 02 14.480453; this version posted February 15,2022 . The copyright holder for this preprint (which was not certified by peer review) is the author/funder, who has granted bioRxiv a license to display the preprint in perpetuity. It is made available under aCC-BY-NC-ND 4.0 International license.

\begin{tabular}{|l|l|c|}
\hline $\begin{array}{l}\text { Bacteroidetes/Actinobacteria } \\
\text { 16S rRNA-F }\end{array}$ & GGT TCT GAG AGG AGG TCC C & Barman et \\
al., 2008 \\
\hline $\begin{array}{l}\text { Bacteroidetes/Actinobacteria } \\
\text { 16S rRNA-R }\end{array}$ & GCT GCC TCC CGT AGG AGT & Barman et \\
al., 2008 \\
rRNA-F
\end{tabular}



available under aCC-BY-NC-ND 4.0 International license.

\begin{tabular}{|c|c|c|c|c|c|}
\hline Score & $\begin{array}{c}\text { Submucosal } \\
\text { edema }\end{array}$ & $\begin{array}{l}\text { Epithelial } \\
\text { damage }\end{array}$ & Exudate & $\begin{array}{l}\text { Submucosal } \\
\text { neutrophil } \\
\text { infiltration } \\
\text { (cells/high } \\
\text { power field) }\end{array}$ & $\begin{array}{c}\text { Submucosal } \\
\text { mononuclear } \\
\text { cell } \\
\text { infiltration } \\
\text { (cells/high } \\
\text { power field) }\end{array}$ \\
\hline 0 & No changes & No changes & No changes & $\begin{array}{c}\text { No changes } \\
(0-5)\end{array}$ & $\begin{array}{c}\text { No changes } \\
(0-5)\end{array}$ \\
\hline 1 & $\begin{array}{l}\text { Detectable } \\
\qquad(<10 \%)\end{array}$ & Desquamation & $\begin{array}{l}\text { Slight focal } \\
\text { accumulation }\end{array}$ & $(6-20)$ & $(5-10)$ \\
\hline 2 & $\begin{array}{c}\text { Mild } \\
(10-20 \%)\end{array}$ & Mild erosion & $\begin{array}{c}\text { Mild focal } \\
\text { accumulation }\end{array}$ & $(21-60)$ & $(10-20)$ \\
\hline 3 & $\begin{array}{l}\text { Moderate } \\
(20-40 \%)\end{array}$ & $\begin{array}{c}\text { Marked } \\
\text { erosion and/or } \\
\text { mild ulceration }\end{array}$ & $\begin{array}{c}\text { Moderate } \\
\text { multifocal } \\
\text { accumulation }\end{array}$ & $(61-100)$ & $(20-40)$ \\
\hline 4 & $\begin{array}{l}\text { Marked } \\
(>40 \%)\end{array}$ & $\begin{array}{l}\text { Multifocal } \\
\text { ulceration }\end{array}$ & $\begin{array}{c}\text { Marked } \\
\text { diffuse } \\
\text { accumulation }\end{array}$ & $(>100)$ & $(>40)$ \\
\hline
\end{tabular}


A

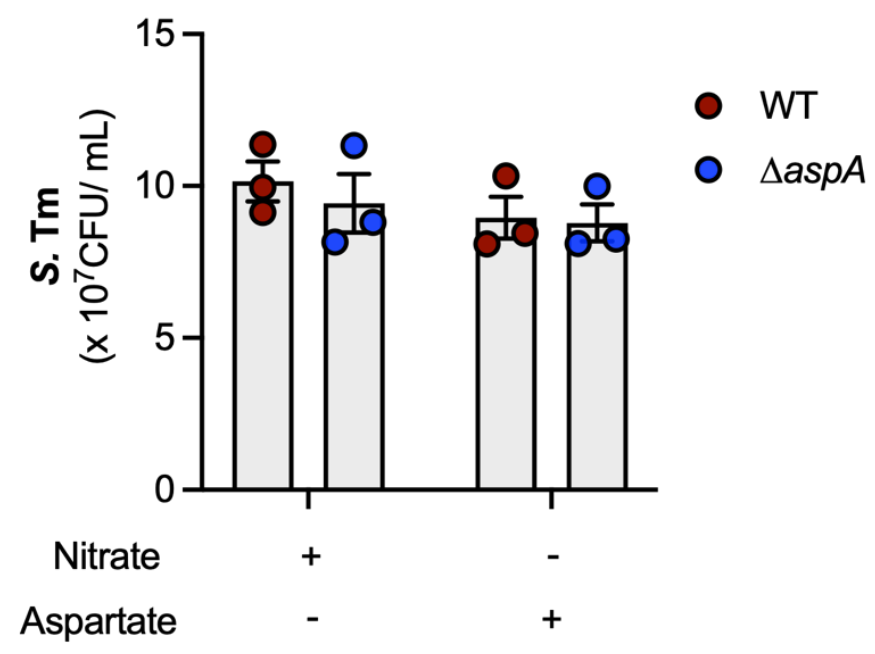

C

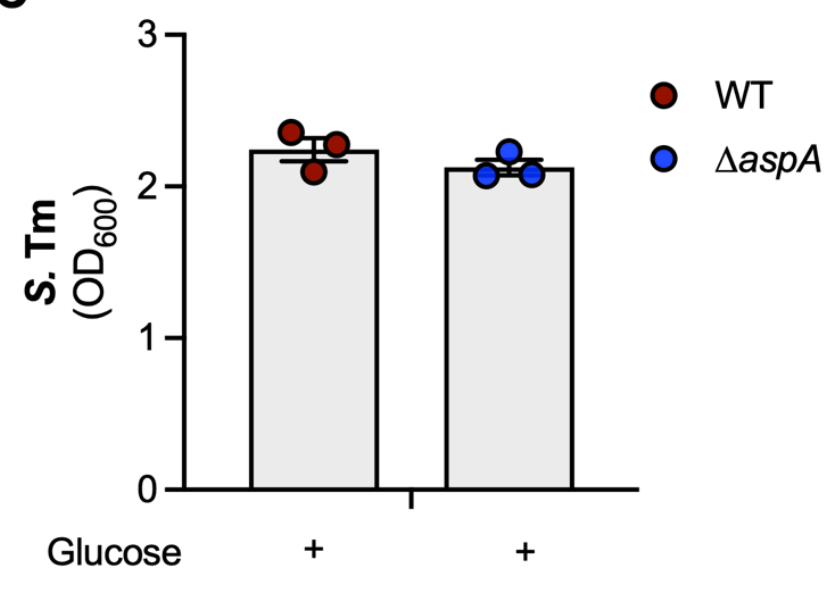

B

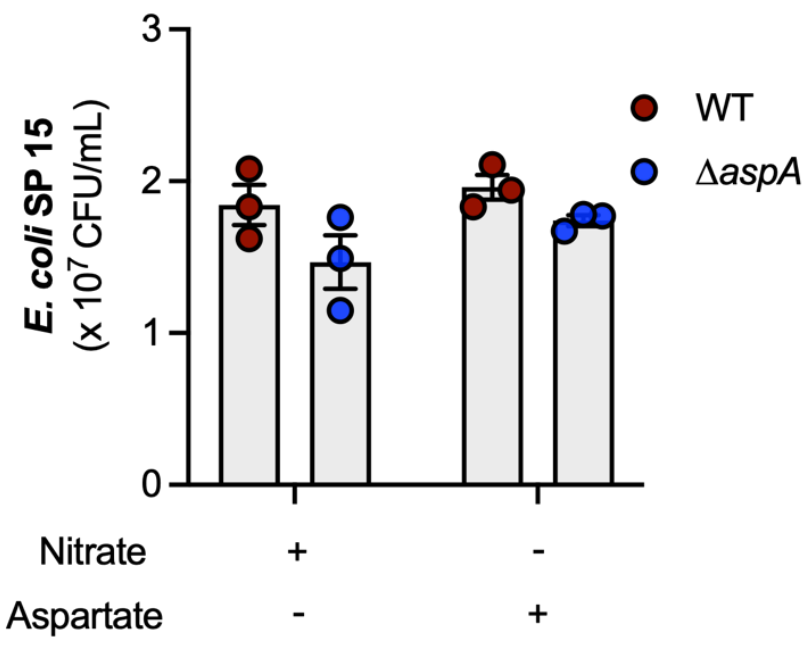

D

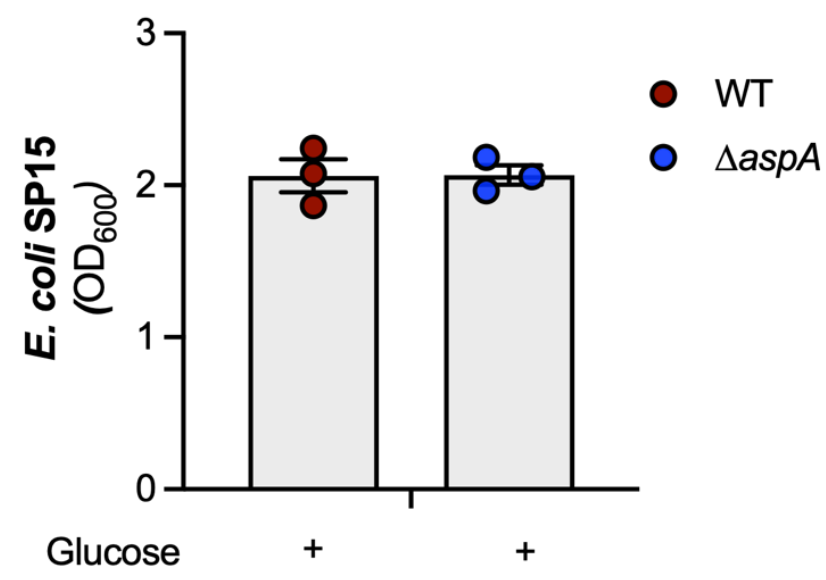

Figure S1. Salmonella enterica serovar Typhimurium and Escherichia coli SP15 $\triangle$ aspA mutants are not defective for growth on nitrate and glucose. Related to Figure 1. (A-B) Wild-type S. Tm (A) and Escherichia coli SP15 (B) and isogenic $\triangle a s p A$ mutants were grown in NCE minimal media supplemented or not with $L$-aspartate $(30 \mathrm{mM})$ or sodium nitrate $(40 \mathrm{mM})$ for 18 hours under anaerobic conditions. (C-D) Wild-type S. Tm (A) and Escherichia coli SP15 (B) and isogenic $\triangle a s p A$ mutants were inoculated with $\mathrm{OD}_{600}=0.1$ and then grown in NCE minimal media supplemented with glucose $(5 \mathrm{mM})$ for 18 hours under anaerobic conditions. Bacterial growth was determined by measuring $\mathrm{OD}_{600}$. Each dot represents one biological replicate (average of triplicate technical replicate per biological replicate). Bars represent mean \pm SEM. 
A
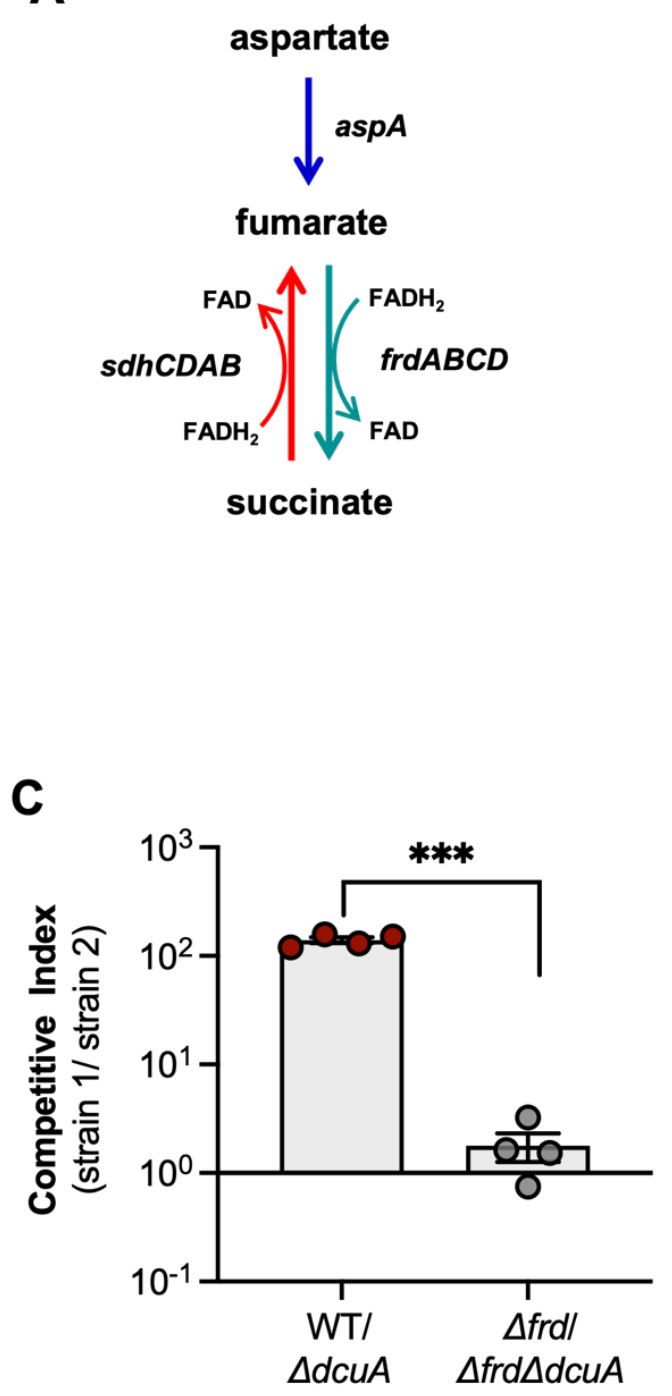

B

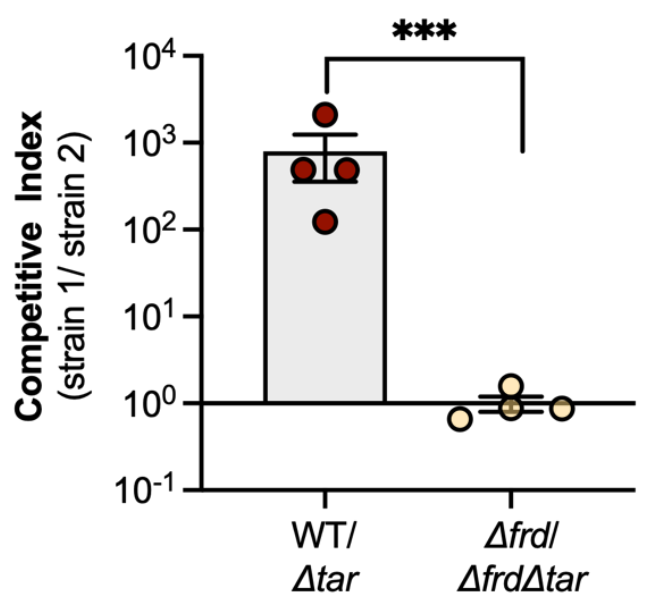

D

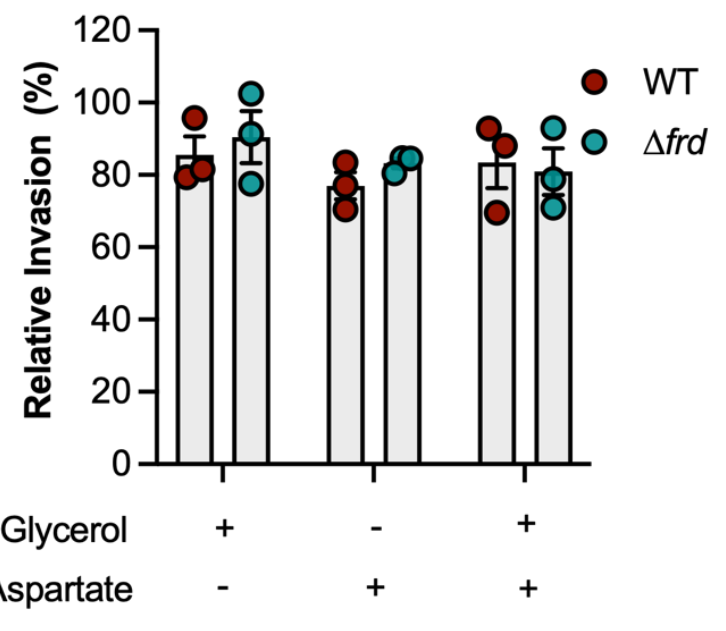

Figure S2. Chemotaxis towards exogenous aspartate and transport of the amino acid support fumarate-dependent anaerobic respiration in vivo. Related to Figure 3. (A) Schematics of aspartatedependent fumarate respiration. (B) Female CBA/J mice were intragastrically infected with $10^{9} \mathrm{CFU}$ of a 1:1 ratio of wild-type $S$. Tm (WT) and isogenic $\Delta$ tar mutant or a 1:1 ratio of $S$. Tm $\Delta$ frd and isogenic $\Delta$ frd/star mutant for ten days. Competitive index in fecal samples was determined at day ten postinfection. (C) Female CBA/J mice were intragastrically infected with $10^{\circ} \mathrm{CFU}$ of a $1: 1$ ratio of wild-type S. Tm (WT) and isogenic $\Delta d c u A$ mutant or a 1:1 ratio of $S$. Tm $\Delta$ frd and isogenic $\Delta$ frd/ $\Delta d c u A$ mutant for ten days. Competitive index in fecal samples was determined at day ten post-infection. (D) Invasion essay in Caco-2 cells of wild-type S. Tm (WT) and isogenic $\Delta$ frd strain. MOI=10. For in vitro experiments, each dot represents one biological replicate (average of triplicate technical replicate per biological replicate). For mouse experiments, each dot represents data from one animal (biological replicate). Bars represent mean \pm SEM. ${ }^{* * *}, p<0.001$. 
A

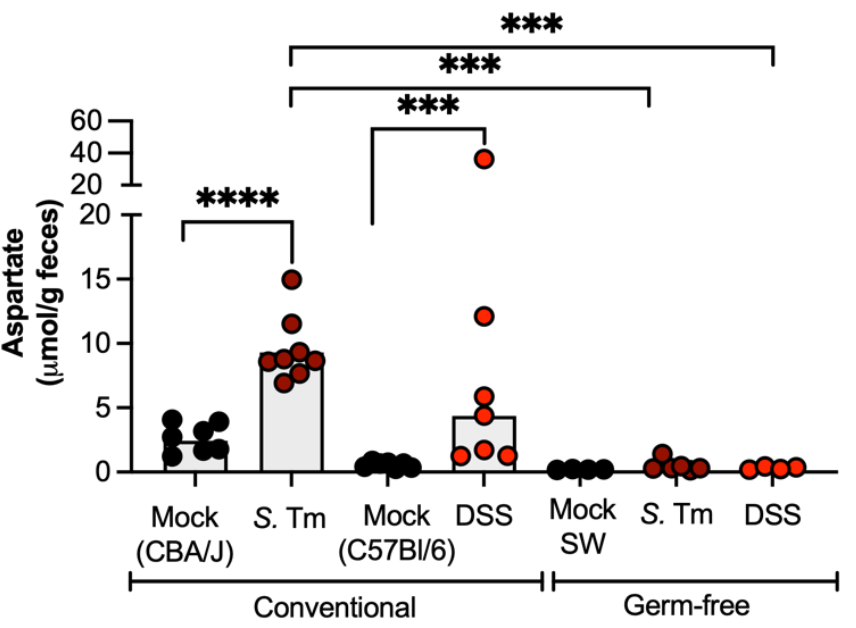

B

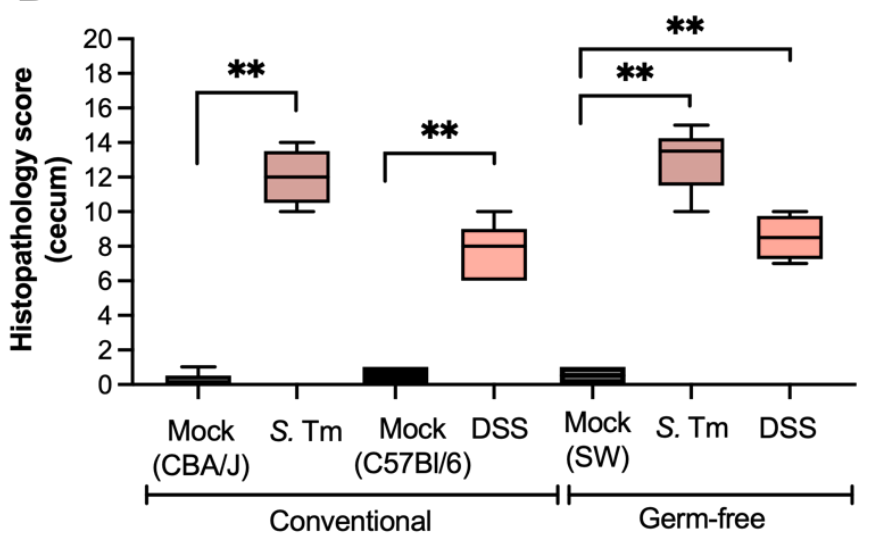

C

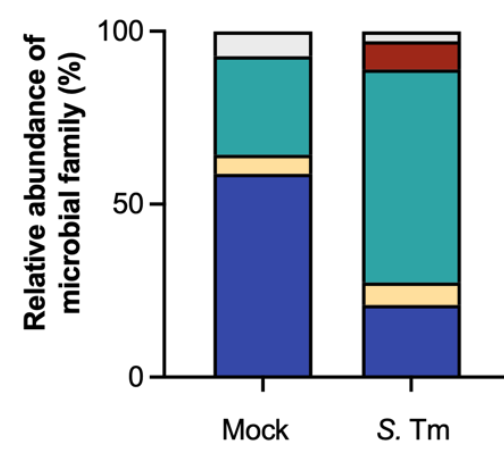

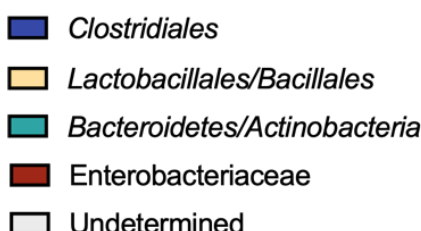

$\square$ Undetermined

Figure S3. Colitis does not result in increased levels of aspartate in the intestinal lumen of germfree mice. Related to Figure 5. (A) Conventional CBA/J and germ-free Swiss Webster (SW) mice were intragastrically infected with $10^{9} \mathrm{CFU}$ of wild-type $\mathrm{S}$. Tm. Conventional C57BI/6J mice and germ-free SW mice were given $2.5 \%$ DSS in the drinking water for seven days to induce colitis. Fecal aspartate levels were measured at day ten post-infection for conventional CBA/J mice, at day three post-infection for germ-free SW mice and at day eight after beginning of treatment for DSS-treated mice. (B) Combined histopathology score of pathological lesions in the cecum of mice from (A) at day ten postinfection for conventional CBA/J mice, at day three post-infection for germ-free SW mice and at day eight after beginning of treatment for DSS-treated mice. $(n=5-8)$. (C) Relative abundance of microbiota members performed by real-time qPCR in fecal samples of female CBA/J mice infected with $10^{9} \mathrm{CFU}$ of wild-type $S$. Tm for ten days. Each dot represents data from one animal (biological replicate). Bars represent mean \pm SEM. The boxes in the whisker plot represent the first to third quartiles, and the mean value of the gross pathology scores is indicated by a line. ${ }^{* *}, p<0.01 ;{ }^{* * *}, p<0.001$. 


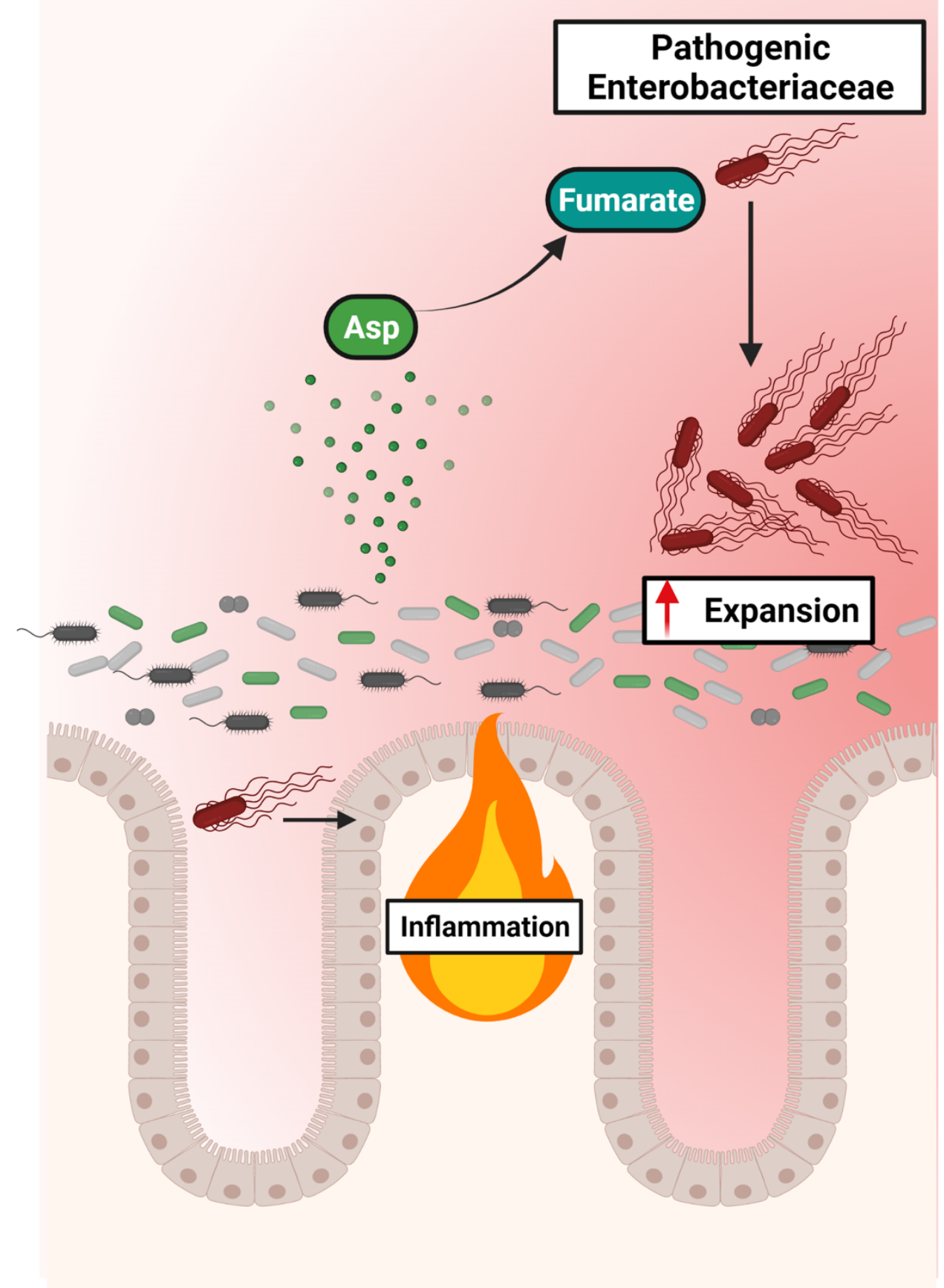

Figure S4. Pathogenic Enterobacteriaceae rely on microbiota-derived aspartate to support fumaratedependent fumarate respiration in the inflamed gut. Created with BioRender.com. 